\title{
The genetics of sports injuries and athletic performance
}

\author{
Nicola Maffulli ${ }^{1}$ \\ Katia Margiotti ${ }^{2}$ \\ Umile Giuseppe Longo ${ }^{3}$ \\ Mattia Loppini ${ }^{3}$ \\ Vito Michele Fazio ${ }^{2}$ \\ Vincenzo Denaro ${ }^{3}$
}

1 Centre for Sports and Exercise Medicine, Queen Mary University of London, Barts and The London School of Medicine and Dentistry, Mile End Hospital, London, UK

Department of Physical and Rehabilitation Medicine, University of Salerno, Italy

2 Department of Surgical Pathology, Campus BioMedico University, Trigoria, Rome, Italy

3 Department of Orthopaedic and Trauma Surgery, Campus Bio-Medico University, Trigoria, Rome, Italy

Corresponding author:

Nicola Maffulli

Centre for Sports and Exercise Medicine,

Queen Mary University of London,

Barts and The London School of Medicine and Dentistry, Mile End Hospital, London, UK

Department of Physical and Rehabilitation

Medicine, University of Salerno, Italy

E-mail: n.maffulli@qmul.ac.uk

\section{Summary}

Purpose: in the last two decades, several evidences have been provided to support the relationship between single nucleotide polymorphisms and the susceptibility to develop injuries participating in sport and performance related to sports activity. We report up-to-date review of the genetics factors involved in tendon injuries and athletic performance.

Methods: we searched PubMed using the terms "sports injuries", "athletic performance" and "genetics" over the period 1990 to the present day. We also included non-English journals.

Results: most of the currently established or putative tendinopathy susceptibility loci have been analyzed by candidate gene studies. The genes currently associated with tendon injuries include gene encoding for collagen, matrix metallopeptidase, tenascin and growth factors. Several genes have been related to the physical performance phenotypes affecting endurance capacity and muscle performance. The most studied include $A C E$ and $A C T N 3$ genes.

Conclusions: genetics determines the response of an individual to the surrounding environment. Recently, some of the individual genetic variations contributing to the athletic performance and the onset of musculoskeletal injuries, particularly in tendon and ligament tissues, have been identified. However, the identification of the genetic background related to susceptibility to injuries and physical performance of the athletes is challenging yet and further studies must be performed to establish the specific role of each gene and the potential effect of the interaction of these.

KEY WORDS: sports injuries, athletic performance, genetics, single nucleotide polymorphisms.

\section{Introduction}

Tendinopathies account for a substantial proportion of overuse injuries associated with sports ${ }^{1}$, and are a common cause of disability ${ }^{2-4}$. Most major tendons, such as the Achilles, patellar, rotator cuff and forearm extensor tendons (amongst others) are vulnerable to overuse, which induces pathological changes in the tendon 5 .

The term tendinopathy as a generic descriptor of the clinical conditions (both pain and pathology) associated with overuse in and around tendons ${ }^{6}$. The histological descriptive term 'tendinosis' (a degenerative pathology with a lack of inflammatory change) and 'tendonitis' or 'tendinitis' (implying an inflammatory process) should only be used after histopathological confirmation ${ }^{6}$. However, it should be kept in mind that, despite the use of the term 'tendinosis', at histopathological examination the essence of a tendinopathic lesion is a failed healing response, with haphazard proliferation of tenocytes, intracellular abnormalities in tenocytes, disruption of collagen fibres, and subsequent increase in non-collagenous matrix ${ }^{7-9}$. Tendinopathic tendons have an increased rate of matrix remodelling, leading to a mechanically less stable tendon which is probably more susceptible to damage ${ }^{10}$. Histological studies of surgical specimens in patients with established tendinopathy consistently show either absent or minimal inflammation ${ }^{11-13}$. They generally also show hypercellularity, a loss of the tightly bundled collagen fiber appearance, an increase in proteoglycan content and, commonly, neovascularisation ${ }^{14,15}$. Inflammation seems to play a role only in the initiation, but not propagation and progression, of the disease process ${ }^{16}$. 
Competing theories have been proposed to explain the pathogenesis of tendon pathology at specific stages and presentations of the condition ${ }^{17-20}$. A continuum of tendon pathology from asymptomatic tendons to tendon tears has been proposed21,22.

Failed healing and tendinopathic features have been associated with chronic overload, but the same histopathologic characteristics also has been described when a tendon is unloaded: stress shielding seems to exert a deleterious effect ${ }^{11}$. Unloading a tendon induces cell and matrix changes similar to those seen in an overloaded state, and decreases the mechanical integrity of the tendon ${ }^{21,22}$.

Genetics is the science of heredity and variation in living organisms. It investigates gene function, genome structure, chromatin organisation, recombination rate, mutation processes, and evolutionary history, to provide a coherent understanding of the human genome and its complex relationship with human biology, physiology and disease. In the last two decades, several evidences have been provided to support the relationship between single nucleotide polymorphisms and the susceptibility to develop injuries participating in sport and performance related to sports activity ${ }^{23}$.

In this current concepts review, we report up-to-date review of the genetics factors involved in tendon injuries and athletic performance.

\section{Candidate genes associated to tendon injuries}

Most of the currently established or putative tendinopathy susceptibility loci were analyzed by candidate gene studies. Indentify genetic susceptibility loci to injury could lead to customize exercise recommendations for specific patient populations. Prevention strategies like avoidance of weight-bearing and high-impact sports for individuals who have risk profile genotypes would take advantage of this information.

\section{COL1A1 (Collagen type I alpha 1 gene)}

Collagen type I fibrils are a major constituent of bone matrix and form strong parallel bundles of fibers in tendons and ligaments. The major two genes that regulate collagen production are the collagen la1 (COLIA1) and the collagen I 22 (COLIA2) gene. The COLIA1 and COLIA2 encode collagen I $\alpha 1$ and collagen l $\alpha 2$ polypeptides, respectively, which associate in a 2:1 ratio to form collagen type $\mathrm{I}^{24}$. The COL1A1 gene (located on chromosome 17q21.33) contains a polymorphism in the region of intron 1 (rs1800012), a predicted binding site for the transcription factor $\mathrm{Sp}_{12}^{25}$. Some studies have shown that the functional Sp1-binding site polymorphism is associated with various complex disorders including osteoporotic fractures $^{25}$, osteoarthritis ${ }^{26}$, myocardial infarction ${ }^{27}$, lumbar disc disease ${ }^{28}$ and stress urinary incontinence ${ }^{29}$. It was proposed that the $\mathrm{G}$ to $\mathrm{T}$ substitution within the intronic Sp1-binding site increases the affinity for the transcription factor Sp1, resulting in increased COL1A1 gene expression and the production of a weaker type I collagen homotrimer consisting of three la1chains instead of the conventional heterotrimers (two l $\alpha 1$ and one l $\alpha 2$ chains) ${ }^{25,30}$. Recently, this polymorphism, has been associated with cruciate ligament ruptures ${ }^{31}$, shoulder dislocation ${ }^{31}$, anterior cruciate ligament ruptures ${ }^{32}$ in two different populations study. Khoschnau et al. ${ }^{31}$ reported that the COLIA1 Sp1 TT genotype was associated with a substantially reduced risk of cruciate ligament ruptures and shoulder dislocation ruptures, they found a substantial $85 \%$ reduced risk (95\% Cl $34 \%$ to $97 \%$ ) of injury for those with the rare TT genotype compared with those with GG genotype. Individuals with the rare genotype TT showed a $4 \%$ prevalence in the 325 Swedish controls analyzed whereas in the 358 injured patients was underrepresented showing only 1 case in the cruciate ligament ruptures group $(0.4 \% ; n=233)$ and 1 case in the shoulder dislocation ruptures group $(0.8 \%$; $\mathrm{n}=126$ ). Posthumus et al. ${ }^{32}$ reported a similar data, showing that the relative genotype frequencies of the COL1A1 Sp1 binding site polymorphism within the asymptomatic 130 white South African controls was of the $4.6 \%$ for the TT genotype while none of the 117 Caucasian patients with surgically diagnosed anterior cruciate ligament ruptures showed a TT genotype. In fact the TT genotype was significantly underrepresented in the anterior cruciate ligament ruptures group compared with the control group $(P=0.031$; $\mathrm{OR}=0.08 ; 95 \% \mathrm{Cl} 0.01$ to 1.46$)$. Finally, Posthumus et al. ${ }^{33}$ had shown no significant association in the allelic or genotype frequencies of the Sp1 binding site polymorphism in 126 patients with Achilles tendinopathy and 126 healthy Caucasian controls. These results suggested that the COL1A1 polymorphism potentially protects from cruciate ligament, shoulder dislocation, and anterior cruciate ligament ruptures ${ }^{31,32}$. A recent short communication reported the combined effect, from the above three published studies, of the rare TT genotype of the COL1A1 Sp1 binding site polymorphism on the risk of acute soft tissue ruptures (cruciate ligament, shoulder dislocation and Achilles tendon ruptures) ${ }^{34}$. A Fisher's exact test was used to analyse any differences in the genotype frequencies (TT vs GT and GG) of the 581 combined control and injured groups in the three published studies. The injured groups were analysed as: 1) 350 cruciate ligament ruptures ${ }^{31,32}$; 2) 476 cruciate ligament ruptures and shoulder dislocation ${ }^{31,32}$ and 3) all 517 soft tissue ruptures (cruciate ligament, shoulder dislocation and Achilles tendon) ${ }^{31-33}$. The rare TT genotype was significantly underrepresented in the cruciate ligament group $(0.3 \%$ TT genotype; $n=1)$ when compared with the control group (4.1\% TT genotype; $n=24)$ of all three published studies $(\mathrm{OR}=15.1 ; 95 \% \mathrm{Cl} 2.0$ to 111.7; $P<0.001)$. Similar results were obtained when the cruciate ligament and shoulder dislocation group (0.4\% TT genotype; $n=2 ; O R=10.2 ; 95 \% \mathrm{Cl} 2.4$ to $43.4 ; \mathrm{P}<0.001)$ or the all soft tissue ruptures group (0.4\% TT genotype; $n=2 ; O R=11.1 ; 95 \% \mathrm{Cl} 2.6$ to 47.2; $\mathrm{P}<0.001$ ) were compared with the control 
group. In summary, the combined results from three recently published studies, show that the TT genotype of the COL1A1 Sp1 binding site polymorphism is underrepresented in acute soft tissue ruptures, in particular of the cruciate ligament group. The clinical relevance of this finding is that the COL1A1 TT genotype seems to have a protective effect on his carriers. However, further larger sample sizes studies must be evaluated for this rare polymorphism, before addressing his protective role on ligament, tendon and other soft tissue ruptures.

\section{COL5A1 (Collagen type V alpha 1 gene)}

Based on its known biological function and chromosome location COL5A1 gene has been selected as specific candidate gene for Achilles tendon injuries, anterior cruciate ligament rupture, and altered musculotendinous flexibility in four different reports coming from the same research institute ${ }^{35-38}$. The COL5A1 gene encodes for the $\alpha 1$ chain of type $V$ collagen, which is a minor fibrillar collagen found in ligaments and tendons, as well as other tissues ${ }^{39}$. Type $\mathrm{V}$ collagen, which makes up approximately $10 \%$ of the collagen content in ligaments, intercalates into the core of type I collagen fibrils, where it is believed to be involved in the organization and regulation of type I collagen fibril diameters ${ }^{40}$. Furthermore, some investigators have reported an association of the $A B O$ blood group with Achilles tendon injury ${ }^{41}$, the $A B O$ blood group is determined by a single gene located on the end of the long arm of chromosome 9 (9q34) close to the chromosomal localization of the COL5A1 gene and other genes that will be discussed further in this review. The COL5A1 gene contains a BstUI and a Dpnll restriction fragment length polymorphisms (RFLPs) within its 3'-untranslated region (UTR) ${ }^{42}$. Some studies investigated whether genetic variants within the COL5A1 gene were associated with Achilles and quadriceps tendon injuries, anterior cruciate ligament rupture, and altered musculotendinous flexibility ${ }^{35-38,43}$.

In particular, Mokone et al. ${ }^{35}$ investigated whether the BstUI (rs12722, C to T substitution) and/or the Dpnll (rs13946, C to T substitution) polymorphisms were associated with Achilles tendon injuries in 111 Caucasian patients and 129 healthy Caucasian controls from a South African population. The main biological finding was a significant difference in the allele distribution of the three COL5A1 BstUI RFLP alleles (A1, $A 2$, and $A 3$ derivating from two single nucleotide polymorphisms substitution: rs12722 and rs557488 $01)$ when controls subjects were compared with the Achilles tendon injuries group $(P=0.006)$. The frequencies of the $\mathrm{A} 1$ and $\mathrm{A} 3$ alleles were higher in the Achilles tendon injuries group $(A 1,76.1 \%$ and $A 3$, $5.9 \%)$ than in the controls group ( $A 1,67.1 \%$ and $A 3$, $3.1 \%$ ), while the frequencies of the A2 allele (corresponding to the $\mathrm{C}$ allele of the rs12722 single nucleotide polymorphism substitution) was significantly higher in the controls subjects (A2, 29.8\%) than in the patients group (A2, 29.8\%). Based on this statistical evidence the authors concluded that individuals with the CC genotype were therefore less likely of developing symptoms of tendon pathology $(\mathrm{OR}=1.9 ; 95 \%$ $\mathrm{Cl} 1.3$ to $3.0 ; P=0.004)^{35}$ (35). Finally, there were no significant differences in the genotype frequencies of the COL5A1 DpnII RFLP alleles between the controls subjects and the Achilles tendon injuries group ${ }^{35}$. Moving from first evidence September et al. ${ }^{36}$ decided to study the association of the COL5A1 gene and the Achilles tendinopathy in two different population, white South African and Australian ${ }^{36}$. The authors selected 7 genetic variants within the COL5A1 gene, the already investigated rs12722 (BstUI RFLP) and rs13946 (Dpnll RFLP) plus 5 other variants (rs10858286, rs3196378, rs11103544, rs4504708 and rs3128575). The first two variants rs12722 and rs13946 were already analyzed in the South African population by Mokone et al. ${ }^{35}$ and as mentioned the rs12722 was strongly associated with chronic Achilles tendinopathy in this study, while the rs13946 was no associated. Thus, the authors evaluated these two variants in a second case-control population study of subjects from Australia, while the other 5 variants were investigated in both South African and Australian population ${ }^{36}$. There was a highly significant difference in the genotype distribution of rs12722 between the Australian controls and Australian Achilles tendon injuries group $(\mathrm{P}=0.001)$. Moreover, individuals with a CC genotype had a significantly decreased risk of developing chronic Achilles tendinopathy than those with a T allele (TC or TT genotype) in both the Australian (OR=0.42; 95\% Cl 0.20 to 0.86 ; $\mathrm{P}=0.017$ ) and South African (OR=0.38; $95 \% \mathrm{Cl} 0.18$ to 0.77 ; $\mathrm{P}=0.008$ ) groups. As for the South African population there was no significant association of the marker rs13946 (Dpnll RFLP) and tendinopathy disease in the Australian population ${ }^{36}$.

A significant difference in the genotype distribution between the Australian controls and Australian Achilles tendon injuries groups was noted for rs3196378, which spans a putative mRNA binding site $(P=0.016)$. The AC genotype was significantly associated with the increased risk of developing Achilles tendon injuries in the Australian population (OR 2.3; 95\% Cl 1.3 to $4.1 ; \mathrm{P}=0.004$ ). These data were not confirmed in the South African study. None of the differences in genotype distribution between the Australian controls and tendon injuries groups for markers rs10858286, rs4504708 and rs3128575 were significant. For this reason, these markers were not analysed in the South African group. In conclusion, the relevant finding of this report was that the COL5A1 BstUI RFLP is associated with Achilles tendinopathy in two independent populations.

Finally, Laguette et al. ${ }^{44}$ investigated the relationship between the sequence of the COL5A1 3'-UTR and the mRNA stability, comparing patients with Achilles tendinopathy and asymptomatic controls.

The predominant forms were T-allele in patients with Achilles tendinopathy and $\mathrm{C}$-allele in the controls. The authors reported a significantly increased mRNA 
stability for T-allele and proposed that it could be a molecular mechanism underlying musculoskeletal soft tissue injuries.

Recently, Posthumus et al. ${ }^{37}$ have shown that the CC genotype of COL5A1 BstUI RFLP polymorphism was also significantly underrepresented in female, but not male, athletes with anterior cruciate ligament rupture. The authors genotyped for the COL5A1 BstUI and DpnII RFLPs 129 white participants (38 of which were women) with surgically diagnosed anterior cruciate ligament ruptures and 216 physically active control participants (84 of which were women) without any history of anterior cruciate ligament injury. When the female and male participants were analyzed together, there were no significant differences in genotype or allele frequencies, whereas when the female and male participants were analyzed separately, the BstUI RFLP CC genotype was overrepresented in the control participants within the female (OR=6.6; 95\% Cl 1.5 to 29.7; $P=0.006$ ), as has been already shown in the previous reports ${ }^{35,36}$ but no association was found in the male participants ${ }^{37}$. These data should be interpreted with caution because of the small sample size of the female participants.

The polymorphisms within the 3'-UTR were further analyzed from Collins et al. ${ }^{38}$ to investigate the possible association with musculotendinous range of motion, because altered musculotendinous flexibility, defined as "the ability to move a joint through its complete range of motion" (ROM) ${ }^{45}$, has been cited as an intrinsic risk factor for musculotendinous injuries ${ }^{46-48}$. The ROM measurements were recorded in all the subjects like sit and reach (SR) test ${ }^{45}$ and passive straight leg raise (SLR) test ${ }^{49}$. The sit and reach (SR) and the passive straight leg raise (SLR) were measured on 119 Caucasian subjects with either a past, current or no history of Achilles tendon injuries ${ }^{38}$. The subjects were genotyped for the Dpnll RFLP (rs13946), BstUI RFLP (rs12722) and two other variants the Acil RFLP (rs3196378, C or A variant) and Mboll RFLP (rs11103544, C or T variant) ${ }^{38}$. The only significant genotype differences distribution was noted in the passive SLR and SR measurements between COL5A1 BstUI RFLP genotype groups, with the heterozygous group (TC genotype) less flexible than the homozygous (TT and CC genotypes) groups. There were, however, no significant differences in any of the ROM measurements between the genotype groups of the other three polymorphisms ${ }^{38}$. Authors concluded that the COL5A1 BstUI RFLP was independently associated with lower limb ROM within that cohort. Subsequently, Brown et al. ${ }^{50}$ investigated the association between COL5A1 BstUI RFLP and SR ROM in healthy and physically active subjects. They found that the COL5A1 BstUI RFLP genotype was associated with SR ROM in subjects over 35 years, with the grater SR ROM associated with TC genotype and the lower with $C C(P=0.017)$. Moreover, COL5A1 genotype interacted significantly with age and sex for SR ROM. Given these results, authors stated that the COL5A1 BstUI RFLP contribute to determine the ROM in older, healthy and physically active subjects. Finally, Brown et al. ${ }^{51}$ also investigated the relationship between COL5A1 genotype, ROM, and ultra-marathon running performance. They reported better endurance running performance in patients with lower ROM (TT genotype) when compared with participants with TC and CC genotypes. Moreover, $T$ allele was found significantly $(P=0.044)$ over-represented in conditions of faster performance and lower flexibility.

\section{COL12A1 (Collagen type XII alpha 1 gene)}

As the COL5A1 gene and the COL1A1 gene any other proteins involved in similar biological processes can be studied to test the association between the selected candidate gene and the Achilles tendon injuries and or anterior cruciate ligament rupture. For this reason it was decided to investigate additional candidate genes such as COL12A1 and COL14A1 gene ${ }^{52,53}$. Types XII and XIV collagens belong to a family of non-fibrillar collagens are associated with the surface of the collagen fibril and are members of the Fibril Associated Collagens with Interrupted Triple helices (FACITs) subfamily ${ }^{54}$. Type XII collagen is a homotrimer consisting of $3 \alpha 1$ (XII) chains and is encoded by a single gene, COL $12 A 1$, mapped to chromosome $6 q 12-q 13^{55}$. Similar to type $V$ collagen, type XII collagen is believed to regulate fibril diameter (fibrillogenesis) ${ }^{56-58}$. September et al. ${ }^{52}$ investigated the association of two COL12A1 single nucleotide polymorphism (SNP rs970547 and SNP rs240736) with Achilles tendon injuries, and reported not significant association in the selected group ${ }^{52}$.

Since tendons and ligaments have a similar hierarchical structure ${ }^{24}$, and previous work suggested that there might be common genetic risk factors for acute soft tissue ruptures ${ }^{34}$, Posthumus et al. investigated the COL12A1 gene as a possible additional genetic risk factor for anterior cruciate ligament rupture as well ${ }^{53}$. One hundred and twenty-nine (38 of which were female) participants with clinically and surgically diagnosed anterior cruciate ligament rupture, as well as 216 (83 of which were female) physically active controls participants without any history of anterior cruciate ligament injury were included in this casecontrol genetic association study. All participants were genotyped for two previously characterised nonsynonymous single nucleotide polymorphisms (SNPs), located within exon 29 (rs240736, a T to C single nucleotide substitution) and exon 65 (rs970547, a A to $\mathrm{G}$ single nucleotide substitution) of COL12A1. The rs970547 is a missense substitution of Gly to Ser at position 3058 and the rs240736 it a missense substitution of Thr to lle at position $1738^{52}$. The differences in genotype or allele frequencies of the rs240736 SNP between the two groups were statistically significant only when the female participants were analysed separately from the male. The AA genotype of the rs240736 SNP increased the risk of developing anterior cruciate ligament injury of 2.4 fold in the female participants (OR $2.4 ; 95 \% \mathrm{Cl} 1.0$ to 5.5 ; 
$P=0.048$ ), while in the male did not have any effects $^{53}$. The other rs970547 was not associated with the disease independently by the gender. The authors reported that the AA genotype of rs240736 SNP within the terminal exon 65 of the COL12A1 gene was associated with a 2.4 fold increased risk of anterior cruciate ligament injury in female, but not male participants. Since the small sample size further investigation are required either for confirmation and/or exclusion of the COL12A1 gene association with anterior cruciate ligament injury.

\section{COL14A1 (Collagen type XIV alpha 1 gene)}

Based on its known biological function COL14A1 gene has been selected as specific candidate gene for Achilles tendon injuries ${ }^{52}$. Unlike the fibrillar collagens, types XIV collagen is associated with the surface of the collagen fibril and are members of the Fibril Associated Collagens with Interrupted Triple helices (FACITs) subfamily ${ }^{54}$. Type XIV collagen is a homotrimeric molecule consisting of $\alpha 1$ (XIV) chains and is encoded by a single gene, COL14A1, mapped to chromosome $8 q 23^{59,60}$. September et al. decided to investigate two informative exonic SNPs of the COL14A1 gene, the $A$ to $C$ transversion at position 90 of the exon 14 (rs4870723) that cause a missense substitution of Asn to His at position 563, and the intronic SNP as well whit high heterozygosity the A to T transversion at position 93 of the intron 43 (rs1563392). The authors selected for this case-control study a total of 137 physically active Caucasian unrelated individuals with chronic Achilles tendinopaty and 44 acute Achilles tendon rupture, and 131 physically active Caucasian without any history of clinical symptomatic Achilles tendon injuries were selected as controls ${ }^{52}$. There were no significant differences in the genotype or allele distribution of the COL14A1 SNPs between any of the affected and control subjects suggesting that the COL14A1 gene is not associated to increased risk of developing Achilles tendinopathy 52 .

\section{TNC (Tenascin C gene)}

Some investigators have reported an association of the $\mathrm{ABO}$ blood group with Achilles tendon injury ${ }^{41}$, these findings suggest that either the $A B O$ gene or a closely linked gene(s) may be associated with tendon injury. In addition, has been reported that persons with blood group $O$ are more susceptible to tendon injuries ${ }^{41,61-63}$. The ABO blood group is determined by a single gene located on the end of the long arm of chromosome 9 (9q34) close to the chromosomal localization of the already discussed COL5A1 gene and of the TNC gene, closely linked to the $A B O$ gene on chromosome $9 q 32-q 34.3^{64}$. The extracellular matrix glycoprotein tenascin-C is expressed in a variety of tissues, including tendons ${ }^{65}$, and is encoded by the tenascin-C (TNC) or hexabrachion (HXB) gene. Tenascin-C binds other compo- nents of the extracellular matrix and cell receptors, and it plays an important role in regulating cell-matrix interactions ${ }^{66}$. In normal adult tendons, it is expressed predominately in regions responsible for transmitting high levels of mechanical force, such as the myotendinous and osteotendinous junctions ${ }^{67-69}$. The TNC gene contains a guaninethymine (GT) dinucleotide repeat polymorphism (a tandem repeat consisting of a repeated 2-base pair sequence of varying lengths in different people) within intron 17. The influence of this polymorphism in the expression of the gene or the biological function of tenascin- $C$ is, to our knowledge, unknown. Mokone et al. ${ }^{70}$ investigated the association of the GT dinucleotide repeat polymorphism of the TNC gene with Achilles tendon injuries. The authors selected 114 physically active white patients with symptomatic Achilles tendon injuries (72 chronic Achilles tendinopathies and 42 acute Achilles tendon ruptures) and 127 apparently healthy physically active white subjects without any history of symptomatic as a control. Eighteen different alleles of the GT dinucleotide repeat polymorphism within the TNC gene were identified within the two groups. There was a significant difference in the distribution of the alleles between the Achilles tendon injuries and control groups $\left(\chi^{2}=51 ; P=0.001\right)$, with the alleles containing 12 and 14 GT dinucleotide repeats being significantly more frequent in the Achilles tendon injuries group $\left(\chi^{2}=21.6 ; \mathrm{P}<0.001\right)$. The alleles containing 13 and 17 repeats were, on the other hand, significantly less frequent in the Achilles tendon injuries subjects $\left(\chi^{2}=42.4 ; \mathrm{P}<0.001\right)$. Alleles were grouped according to those significantly overrepresented, containing 12 or 14 GT dinucleotide repeats $(\mathrm{O})$, those significantly underrepresented, containing 13 or 17 repeats $(U)$, or alleles evenly distributed $(E)$, and were then paired by genotype and the genotype distribution were analyzed between case and control. Subjects with a genotype of UU or UE were significantly underrepresented in the Achilles tendon injuries group $(\mathrm{OR}=6.2 ; 95 \% \mathrm{Cl} 3.5$ to $11.0 ; P<0.001)$. With respect to the $\mathrm{O}$ alleles, subjects who were either homozygous or heterozygous were overrepresented in the Achilles tendon injuries. The novel finding of this study was that the allele distributions of the GT dinucleotide repeat polymorphism within the TNC gene were significantly different between the subjects presenting with symptoms of Achilles tendon injuries and the asymptomatic subjects. Alleles containing 12 and 14 GT repeats were overrepresented in subjects with Achilles tendon injuries, while the alleles containing 13 and 17 repeats were underrepresented ${ }^{70}$.

\section{MMP3 (Matrix metallopeptidase 3 gene)}

Besides the genes which encode for the extracellular matrix proteins already discussed, the genes that encode for any protein that regulates tendon and ligament biological processes, such as adaptation, healing and remodelling are probably also associated with 
them injuries ${ }^{71,72}$. Raleigh et al. ${ }^{73}$ investigated the role of the matrix metalloproteinases (MMPs) proteins in the etiology of tendinopathy. The MMPs have regulatory roles in maintaining extracellular matrix (ECM) homeostasis. The MMPs are known to consist of over 20 distinct endopeptidases that can catalyse a broad spectrum of both ECM and non-ECM substrates ${ }^{74}$. One of the family, MMP3, can catalytically degrade multiple substrates including: types II, IV, V, IX, X collagens, laminin, fibronectin, proteoglycan, decorin and aggrecan ${ }^{74,75}$. The MMP-3 gene is located at the long arm of chromosome 11 (11q22.3), in cluster together with five other MMP genes (MMP-7 and MMP$10,-11,-12,-13)^{76}$. The promoter region of $M M P-3$ is characterized by a $5 \mathrm{~A} / 6 \mathrm{~A}$ promoter polymorphism at position -1171 , in which one allele has six adenosines (6A) and the second has five adenosines (5A). Has been shown that expression of the MMP3 gene can be substantially altered by the $5 \mathrm{~A} / 6 \mathrm{~A}$ promoter polymorphism ${ }^{77}$ and this variant has been associated with a number of pathological states ${ }^{78,79}$. Interestingly, reduced levels of MMP3 mRNA 80,81 , and immunochemically detectable MMP3 protein have been observed in resected Achilles tendinopathy tissue compared to control tissue ${ }^{81}$. Raleigh et al. ${ }^{73}$ investigated the relationship between variants within the MMP3 gene and Achilles tendinopathy or Achilles tendon rupture. One hundred and fourteen Caucasian subjects diagnosed with Achilles tendon injuries were recruited (including 75 with chronic Achilles tendinopathy and 39 with partial or complete ruptures of the Achilles tendon). An additional, 98 apparently healthy, unrelated, Caucasian subjects were recruited as controls. Three exonic SNPs were identified and selected for this casecontrol study. The rs679620 (E45K) and the rs602128 (D96D) within exon 2 and rs520540 (A362A) within exon 8, all with an high heterozygous frequency and therefore considered potentially informative ${ }^{73}$.

There were no significant differences in the genotype and allele distributions of the selected SNPs between the Achilles tendon injuries and control groups. Since differences have been detected in genotype distributions between subjects with chronic Achilles tendon or Achilles tendon ruptures ${ }^{52}$, the Achilles tendon pathology group was sub-divided into 75 patients with chronic Achilles tendinopathy and 39 patients rupture sub-groups. There were significant differences in the distribution of the genotype $(P=0.031)$ and allele $(\mathrm{P}=0.037)$ frequencies of the MMP3 rs679620 SNP between the control and 75 patients with chronic Achilles tendinopathy. The GG genotype was significantly more frequent in the chronic Achilles tendinopathy $(37.3 \% ; n=28)$ when compared to the control group (19.4\%; $n=19)(\mathrm{OR}=2.5 ; 95 \% \mathrm{Cl} 1.2$ to 4.9; $P=0.010)$. The CC genotype of SNP rs591058 was over-represented in the chronic Achilles tendinopathy $(35.6 \% ; n=26)$ compared to the CON $(19.6 \% ; n=19)(O R=2.3 ; 95 \% \mathrm{Cl} 1.1$ to $4.5 ; P=0.023)$ and the AA genotype of SNP rs650108 was over-represented in the chronic Achilles tendinopathy $(9.5 \%$; $\mathrm{n}=7)$ compared to the $\operatorname{CON}(2.1 \% ; \mathrm{n}=2)(\mathrm{OR}=4.9$;
95\% Cl $1.024 .1 ; P=0.043)$. There were, however, no significant differences in the distribution of the genotype and allele frequencies of the three MMP3 SNPs between the control and the 39 patients rupture subgroup. The authors evaluated the MMP3 rs679620 G/A and COL5A1 rs12722 C/T genotype pairs, together with their frequencies within the 75 patients with chronic Achilles tendinopathy and control groups, as well as their estimated risk (OR) and the risk order. The MMP3 rs679620 A allele (AA or AG genotype) combined with the COL5A1 rs12722 CC genotype had the lowest risk for Achilles tendinopathy ${ }^{73}$. In conclusion, the authors reported the evidence that variation within the human MMP3 gene is associated with Achilles tendinopathy. They also studied and discovered an interaction of the MMP3 variant and the COL5A1 gene variant to increase risk of Achilles tendinopathy. Further study and repetition of this work in other, larger population analysis must to be done to confirm these associations.

Recently, Malila et al. ${ }^{82}$ investigated the relationship between $-16125 \mathrm{~A} / 6 \mathrm{~A}$ polymorphism of the MMP-3 gene and anterior cruciate ligament $(A C L)$ rupture, evaluating 86 patients with ACL ruptures and 100 healthy controls without history of ligament or tendon injuries. They found that $5 A+(5 A / 5 A, 5 A / 6 A)$ genotype and $5 A$ allele frequencies were significantly higher in subjects participating in contact sports when compared with those participating in non-contact sports. Given these results, the authors proposed the $-16125 \mathrm{~A} / 6 \mathrm{~A}$ polymorphism as risk factor for ACL rupture.

\section{TGFB1 (Transforming growth factor beta 1 gene)}

To study further candidate genes as possible predisposing factors to Achilles tendon pathology, Posthumus et al. ${ }^{83}$ selected a functional polymorphism of the TGFB1 gene (the TGFB1 rs1800469 variant) and investigated the association with Achilles tendon pathology within an Australian and a South African case-control cohort study. The TGF-b superfamily, which includes various growth/differentiation factors (GDFs), plays an essential role in tissue (including tendon) growth and homoeostasis. Two members of this family, TGF-b1 (an isoform of TGFb) and GDF-5, have been shown to increase mechanical strength after gene transfection in experimentally injured animal Achilles tendons ${ }^{84-86}$. The GDF-5 gene will be discussed further in this review, TGF-b1 is released in response to a number of stimuli (including mechanical loading ${ }^{87}$ ) and is known to increase cell proliferation, migration and the synthesis of extracellular matrix. The gene coding for TGFb1, TGFB1, is located on chromosome 19q13. The 5' untranslated region (UTR) of the TGFB1 gene contains a functional promoter single nucleotide polymorphism (SNP) (rs1800469, C to T substitution) that has been associated with various multifactorial pathologies ${ }^{88-94}$. Moreover, retrospective regression analysis estimated the mean acid-activated 
TGF-b concentration to be approximately twice as high in the TT genotype compared with the CC genotype of the TGFB1 rs1800469 variant ${ }^{95}$. Posthumus et al. ${ }^{83}$ enrolled subjects from the Australian cohort study ${ }^{36}$, in particular selected 59 Caucasian patients all of which were diagnosed with chronic Achilles tendonopathy and 142 healthy subjects as controls. While from the South African cohort study ${ }^{35,70}$ selected 112 Caucasian subjects diagnosed with Achilles tendon pathology and 96 healthy subjects as controls. The genotype and allele frequency of the TGFB1 rs1800469 variant shows no significant differences between the Achilles tendon pathology and controls groups within the South African and/or the Australian cohorts ${ }^{83}$. In conclusion, the study suggests that the TGFB1 polymorphism rs1800469 is unlikely a predisposition factor for the Achilles tendon pathology disease, especially in subjects of European descent.

\section{GDF-5 (Growth/differentiation factor-5 gene)}

The specific role of GDF-5 in tendon is largely unknown ${ }^{55,96}$. GDF-5 is involved in the maintenance, development and repair of bones, cartilage and various other musculoskeletal soft tissues (including tendons) $55,96,97$. The gene coding for GDF-5, GDF5, is located on chromosome 20q11. Mutations within the GDF5 gene are known to cause several inherited developmental disorders ${ }^{98-100}$. A possible role of GDF-5 in tendon and ligament biology was first suggested by Wolfman et al. ${ }^{101}$. In this study, ectopic administration of GDF-5 resulted in the synthesis of new tendon tissue. The 5' UTR of the GDF5 gene contains a functional promoter SNP (rs143383; T to C substitution) that has been associated with multifactorial disorders such as osteoarthritis ${ }^{102}$ and congenital hip dyspla$\mathrm{sia}^{103}$, as well as phenotypic data such as height, hip axis length and fracture risk ${ }^{103}$. The function of this SNP has been reported by luciferase reported assays ${ }^{104}$ and differential allelic expression analysis ${ }^{105,106}$. The T allele of the GDF5 rs143383 was correlated with reduced expression of the GDF5 gene within a wide range of soft tissues ${ }^{105,106}$. To further investigate the role of GDF-5 in tendon, Posthumus et al. ${ }^{83}$ decided to determine whether the functional polymorphisms rs14338 of the GDF5 gene was associated with Achilles tendon pathology within an Australian and a South African case-control cohort study. Given the known functional effect of the chosen SNP, the hypothesis was that the TT genotype of the GDF5 rs143383 variant increases the risk of Achilles tendon pathology. There were significant genotype differences between the Australian chronic Achilles tendonopathy and Australian controls groups for the GDF5 rs143383 variant $(P=0.027)$. Although similar frequencies and trends were observed within the South African cohort, there were no significant genotype or allele differences. When the data from the Australian and the South African cohort were combined, both genotype $(P=0.013)$ and allele $(P=0.019)$ frequencies were significantly different between the case and control groups. Similar results were observed when individuals with a TT genotype for the GDF5 rs143383 variant were compared with individuals with a $C$ allele (combined TC and CC). Within the Australian cohort, the TT genotype increased the susceptibility to Achilles tendonopathy by 2.24 times $(\mathrm{OR}=2.24 ; 95 \% \mathrm{Cl} 1.21$ to $4.16 ; \mathrm{P}=0.011)$. Although there was a similar pattern in the South African cohort, the TT genotype was not significantly over-represented in the Achilles tendonopathy. The TT genotype remained significantly over-represented when both cohorts (Australian and the South African) were analysed together $(\mathrm{OR}=1.82 ; 95 \% \mathrm{Cl} 1.23$ to 2.74 ; $\mathrm{P}=0.004)$. The main finding of this study was that the GDF5 gene was associated with Achilles tendon pathology within an Australian population, independently, and when combined with an additional South African population 83 .

\section{Candidate gene associated to physical perfor- mance}

Physical and athletics performance depend upon a variety of biological and mechanical tissue properties. Such properties may be metabolic or anatomical, including, for example choice of substrate and efficiency of use or tendon length, tendon elasticity, muscle tension properties and fibre types. All of these different phenotypes are related by a complex interplay among the environment and the individual genetic profile. The general hypothesis is that there is an inheritance component affecting physical and athletic fitness that is able to interact with environmental factors, particularly with training. Until the 1990s, the study of such complex traits was based almost entirely on twin and family analyses and on association studies. In the last decade, it has been possible to investigate complex traits, such as physical performance, using molecular biological techniques. Candidate gene loci have been identified related to a variety of performance phenotypes which might relate to athletic phenotype. The most recent update of the 'Human Gene Map for Performance and Health-Related Fitness Phenotypes reported a total of 221 autosomal and X-linked genes and 18 mitochondrial markers that have shown to be associated with a relevant genotype in at least one study, whereas 119 QTL have been reported for exercise- or physical activity related traits ${ }^{107}$. Here we mainly review the most studied genes that have been considered to have a direct influence on physical performance or fitness phenotypes of the athlete. In particular, we will review the literature related to association studies and the $A C E$ gene, which is most extensively studied of any other gene, with at least 60 articles examining the effect of an insertion/deletion polymorphism on fitness and performance traits. In addition to ACE, another gene has been recently characterized by a great attention in numerous scientific articles related to physical and athletic fitness, the ACTN3 gene. 


\section{ACE (Angiotensin-converting enzyme gene)}

The most extensively studied gene in sports and physical performance is the ACE gene ${ }^{108,109}$. In 1998 , Montgomery et al. were the first to publish evidence for an association of improved physical performance and $A C E$ gene ${ }^{110}$. This gene map on chromosome 17q23.3 and encodes an enzyme, the Angiotensin 1-converting enzyme involved in catalyzing the conversion of angiotensin I into a physiologically active peptide angiotensin II. Angiotensin II is a potent vasopressor and aldosterone-stimulating peptide that controls blood pressure and fluid-electrolyte balance. This enzyme plays a key role in the renin-angiotensin system. Many studies have associated the insertion/deletion (I/D) polymorphism of a $287 \mathrm{bp}$ Alu repeat element in intron 16 of this gene with individual variability in exercise-related phenotypes, and particularly in muscle phenotypes. Besides regulating blood pressure, the $A C E$ is expressed in skeletal muscle, where it may influence its function and biomechanical properties ${ }^{111-113}$. The ACE D allele is associated with higher concentration of circulating and tissue ACE, thus increased angiotensin II levels ${ }^{112}$; this allele would theoretically favour performance in more power or strength-oriented sports such as weightlifting. Indeed, the D allele has been associated with elite "sprint" athletic performance ${ }^{108,109}$ and power-related phenotypes in non-athletic populations, like lower risk of skeletal muscle damage induced by eccentric contractions ${ }^{114}$, or greater gains in knee extensor strength after training in old ( $\geq 60$ years) individuals $^{115}$. Conversely, the I allele is theoretically associated with a decrease in circulating levels of angiotensin II with reduction in vascular resistance, which might facilitate cardiac output during strenuous exercise ${ }^{112}$. The I allele could also favour muscle efficiency, a key determinant of long-distance running performance ${ }^{116}$, indicating that these allele, as has been frequently reported, is more frequent in elite endurance athletes ${ }^{108,117}$, while the $D$ allele is more frequent among those engaged in more power oriented sports ${ }^{108,118}$. These results were recently confirmed in a study carried out on 39 Portuguese Olympic swimming candidates, who were stratified into two homogeneous groups: short distance swimmers (SDS), between 50 and $200 \mathrm{~m}$ (mainly anaerobic events) and middle distance swimmers (MDS), 400-1.500 m (mixed anaerobic and aerobic events) ${ }^{119}$. Moreover a group of 32 non-elite swimmers were studied and classified as well, and a control group $(n=100)$ was selected from the Portuguese population. The authors found higher DD genotype $(P=0.029)$ and allelic frequency $(P=0.021)$ of the elite short distance swimmers (SDS) when compared with controls ${ }^{119}$. These results support previous observations, demonstrating an association of the $\mathrm{D}$ allele with elite short-distance swimmer status ${ }^{109,118,120}$, and the relation of the D allele with more power oriented sports. However, the power of the performed test was $<0.80$, hence as the author mentioned, these date should interpret cautiously. Another recent study by Papadimitriou et al. ${ }^{121}$ suggested a weak association of the DD genotype with more power oriented sports. The authors assessed 101 Greek athletes (including 73 power-oriented athletes and 34 sprinters) and 181 controls, showing that sprinters had higher frequency of the DD genotype when compared with the control group (55.8\% vs $31.5 \%)$. Furthermore, there was a trend of increased frequency of both II and DD genotypes in the elite endurance athletes group, as compared to the controls, even though these results were not statistically significant.

However, evidences about the association of $A C E$ polymorphisms and athletic phenotype are not definitive. Amir et al. ${ }^{122}$, observed that the $\mathrm{D}$ allele is more frequent in Israeli marathon runners than in sprinters. Moreover, some authors demonstrated that the $A C E$ I/D polymorphism and A22982G polymorphisms are not associated with elite endurance athlete status in Kenyans ${ }^{123}$ and Ethiopians ${ }^{124}$.

Uncovering the influence of a gene on an heterogeneous phenotype can be difficult, a rare well defined extreme phenotype is easily associated with a rare gene mutation, but the challenge of associating the ACE I/D polymorphism with different sport disciplines and/or continuous variable like left ventricular mass (LV), Maximal Oxygen Uptake $\left(\mathrm{VO}_{2 \mathrm{max}}\right)$, or Bone Mineral Density (BMD) is not so simple: the polymorphism is common with I allele frequency of $50 \%$, and sport performance and continuous variable can depend on several environmental and biological factors including exercise, sex, age race, to overcome such noise these studies needs very large population sample (several hundreds) to reach sufficient statistical power for making solid conclusion. One possible approach is conducting genome-wide linkage analysis studies, which are used to analyze the linkage between hundreds of polymorphisms and a given disease phenotype, eg, obesity or type 2 diabetes. To this end, a recent genome-wide linkage scan study estimated the heritability of athlete status at $60 \%{ }^{125}$. The authors studied 1.210 single-nucleotide polymorphisms (SNPs) in 4.488 British adult female twins and elite status was assumed for those reaching county or national level. However future association studies should be done to clarify the possible role of the genes identified in this study with the athlete status.

\section{ACTN3 (Alpha-actin 3 protein gene)}

The alpha-actin 3 gene (ACTN3) named the "speed gene"126,127 recently has received the most attention for his association with sports performance. This gene encode the $\alpha$-actinin-3 protein, which is, together the $\alpha$-actinin- 2 protein, an important structural component of the $\mathbf{Z}$ disc, where they anchor actin thin filaments, helping to maintain the myofibrillar array ${ }^{128,129}$. Several independent studies have established that the absence of alpha-actinin-3 protein is detrimental to sprint and power performance in athletes and in the general population ${ }^{130-136}$. In humans, $\alpha$-actinin-2 is expressed in all skeletal muscle fibers, 
while $\alpha$-actinin- 3 is expressed only in type 2 fibers. The $\alpha$-actinin-3 gene (ACTN3) has attracted considerable attention due to a frequent nonsense polymorphism R577X (rs1815739) that may influence muscular performance ${ }^{132-135}$, this is due to a cytosine to thymine transition at codon 577 of the ACTN3 gene that results in the replacement of an arginine residue ( $R$ allele) by a premature stop codon ( $X$ allele), thus individuals homozygous for the $\mathrm{X}$ allele do not produce ACTN3 protein in their muscle, and in these cases the ACTN2 gene which is expressed in both type I and II myofibers, it can compensate for the loss of the ACTN3 protein in type II fibers in individuals who are $577 \mathrm{X}$ homozygotes. It has been proposed that the physiological consequences of an $\alpha$-actinin-3 deficiency include differences in fibre type composition of human muscle ${ }^{137}$. ACTN3 deficiency in mice leads to a shift in muscle metabolism towards aerobic pathways, resulting in enhanced distance running ability, but reduced muscle force generation ${ }^{138}$. The R577X polymorphism is found in every human population, with a wide variation, from $1 \%$ in Africans to $25 \%$ in Asian. Yang et al. ${ }^{130}$ were the first to demonstrate highly significant associations between ACTN3 genotype and athletic performance, $50 \%(53 / 107)$ of elite white sprint athletes had the RR genotype, compared with $30 \%(130 / 436)$ and $31 \%(60 / 194)$ of healthy white control participants and elite endurance athletes, respectively. While elite endurance athletes had a slightly higher frequency of the $X X$ genotype $(24 \%)$ than did controls (18\%). From this research, it appears that the presence of the ACTN3 protein (577R) might be associated with greater success in activities requiring sprint or power performance. On the other hand the ACTN3 deficiency (577X) may provide some sort of advantage for endurance athletes. These results were confirmed in several human association studies that have shown a positive association between the $577 \mathrm{X}$ allele and elite endurance athlete performance ${ }^{133-135}$ and several other studies have shown a positive association between the 577R allele with power athletic status ${ }^{130,132-135,139}$ and sprint performance ${ }^{140}$. Recently, Eynon et al. ${ }^{141}$, have evaluated the ACTN3 R577X polymorphism in the Israeli population, in particular were analyzed 155 athletes (119 men and 36 women) and 240 non-athletic healthy individuals as controls. Considering that the athletes were divided into two groups: 1) endurance-type group that included 74 long distance runners whose main events were the $10.000 \mathrm{~m}$ run and the marathon; 2) sprint-type group that included 81 sprinters whose main event was the 100-200 m dash, the authors demonstrated a significantly higher proportion of the $\mathrm{XX}$ genotype in the first group of endurance athletes (32\%) compared with the sprinters $(14 \% ; P=0.005)$ and the controls $(18 \% ; P=0.006)$ groups. Furthermore, according to their individual best performance, athletes within each group were further divided into two subgroups: top level (those who had represented Israel in world track and field championships or in the Olympic Games) and national-level. A comparison between the top-level and na- tional-level sprinters revealed that the $\mathrm{R}$ allele is more frequently found in the top-level sprinters. However, top-level and national-level endurance athletes had similar allele and genotype frequencies. The data support the hypothesis that the ACTN3 $\mathrm{R}$ allele is associated with top-level sprint performance but that the $X$ allele and $X X$ genotypes may not be critical to endurance performance. Several other studies have provided no evidence for associations between endurance athlete performance and XX genotype, suggesting that this association in not as strong as the association with reduced performance in sprint and power activities ${ }^{133,142-147}$. On the other hand, Shang et al. ${ }^{148}$, while were investigating the frequency of the ACTN3 R577X polymorphism among Han Chinese athletes, reported that the $X X$ genotype (21.2 vs. $15.8 \% ; P=0.02$ ) and $X$ allele (51.3 vs. $41.1 \%$; $P=0.019)$ were significantly over-represented in female endurance athletes compared to controls, while no genotype-related differences were observed in male endurance athletes. Consequently it is possible that all the different results in the previous case-control studies of ACTN3 genotype were due to sexual and racial specific differences. Ahmetov et al. ${ }^{149}$ also demonstrated that ACTN3 XX genotype frequency was significantly lower in Russian subelite and elite speed skater sprinters compared with control subjects (2.6 vs $14.5 \% ; P=0.034)$. The authors also showed a positive relationship between the preferred racing distance (PRD) and the proportion of slowtwitch muscle fibres $(r=0.593, P<0.0005)$ in 34 subelite Russian speed skaters (20 men and 14 women), competing in races of different length (500-10.000 m). Finally, they demonstrated that R577X polymorphism was associated with muscle fibre composition (the amount of slow-twitch fibres in RR, RX and $X X$ genotypes was $12.8 \%, 13.2 \%$ and $16.3 \%$ respectively; $\rho=0.215 ; \mathrm{P}=0.049)$ and $\mathrm{PRD}$ of all athletes $(\rho=0.24$, $\mathrm{P}=0.010$ ), showing that ACTN3 XX genotype carriers have a higher proportion of type I fibres and prefer to skate long-distance races.

Recently, the impact on physical performance of combination of polymorphisms involving ACTN3 gene and other several genes has been investigated ${ }^{150,151 .}$ Ginevičiene et al. ${ }^{151}$ studied the association between the polymorphisms of $A C E$ and ACTN3 genes in elite athletes and controls from the Lithuanian population. They reported that athlete carriers of the $A C E \mathrm{l} / \mathrm{l}$ and I/D as well as ACTN3 $\mathrm{X} / \mathrm{X}$ and $\mathrm{R} / \mathrm{X}$ genotypes have better results in terms of grip strength and vertical jump. Chiu et al. ${ }^{150}$ assessed the ACE, ACTN3, peroxisome proliferator-activated receptor delta $(P P A R D)$, and peroxisome proliferator-activated receptor gamma coactivator-1 alpha (PPARGC1A) genes and physical performance in 170 Taiwanese sedentary adolescent girls. At the individual gene analysis, they reported better performance in handgrip strength, 30- and 60-s sit-up tests, and standing long jump for subjects with the ACE D/D, ACTN3 R/R and $P P A R D$ T/C genotypes. In the gene combination analysis, the authors demonstrated that individuals with ACE D/D, ACTN3 R/R and PPARD T/T genotype 
have significantly greater performance in handgrip strength.

So far, other genetic variants in the ACTN3 gene have not been investigated in relation to endurance performance, power athletic status and sprint performance. Further investigations are needed to clarify the possible role of other polymorphisms and the combination of polymorphisms in determining sports performance.

\section{Other gene related to fitness phenotype}

It is thus evident that strong genetic influences interact with environmental stimuli to alter performance traits and other phenotype responses to training. Understanding the genetics factor would give new insight in the explanation of differences in athletic performance. It is important to understand which are the genes strongly influencing critical physiological pathway, for example ACE and ACTN3 genotypes could become an important guide for determining the best suited discipline a young athletes should follow. However, we have just began to recognise some important genetic component involved in the athletic performance and we need more longitudinal studies of large cohorts of young athletes before we could benefits of a genetic testing.

The creatine kinase isoenzyme MM (CK-MM) gene encodes the cytosolic muscle isoform of CK responsible for the rapid regeneration of ATP during intensive muscle contraction. Human studies of $C K-M M$ gene sequence variation have shown a significant association between polymorphisms in this gene, increased cardiorespiratory endurance as indexed by maximal oxygen uptake following 20 weeks of training ${ }^{152}$, peak performance and less decline in force generation ${ }^{153}$. In particular, the A/G polymorphism in the 3' untranslated region of $C K-M M$ contributes to individual running economy responses to endurance training ${ }^{154}$. Recently, Miranda-Vilela et al. ${ }^{155,156}$ have also showed that CK-MM Taql polymorphism could indirectly influence performance affecting the susceptibility to exercise-induced inflammation.

Myosin light chain kinase (MLCK), a calcium-calmodulin dependent multi-functional enzyme, plays a critical role in the regulation of smooth muscle contraction. Polymorphisms in this gene, especially the C37885A allele, are associated with post-exercise strength loss. Heterozygotes for this polymorphism also demonstrate greater strength loss compared with the homozygous wild type (CC $)^{157}$.

Adenosine monophosphate deaminase 1 (AMPD1) is a highly active enzyme in the skeletal muscle that plays an important role in the adenine nucleotide catabolism. A nonsense $\mathrm{C}$ to $\mathrm{T}$ transition in nucleotide 34 (C34T) in exon 2 of AMPD1 gene converts the codon CAA into the premature stop-codon TAA. Subjects with the TT genotype at the C34T AMPD1 gene have diminished exercise capacity and cardiorespiratory responses to exercise in the sedentary state ${ }^{158}$. Moreover, carriers of the $\mathrm{T}$ allele have a limited train- ing response of ventilatory phenotypes during maximal exercise ${ }^{158}$ and a reduced submaximal aerobic capacity ${ }^{159}$. Recently, Cięszczyk et al. ${ }^{160}$ reported a significant deficiency of the $\mathrm{T}$ allele in the polish elite and non-elite rowers compared to control samples, showing that it can be considered a negative factor to athletic performance. The same group also confirmed these results in high-level Polish power-oriented athletes, suggesting that the $\mathrm{C}$ allele may contribute to attain elite status in power-oriented sports ${ }^{161}$.

The insulin-like growth factor 1 protein (IGF-1) increases muscle mass and possibly strength. Accordingly, carriers of the 192 allele of the IGF-1 promoter microsatellite are characterized by greater quadriceps-muscle strength gains compared with non-carriers ${ }^{162}$. However, this study included older subjects (aged 52-81), who have different metabolic characteristics, especially in terms of growth factor levels, cytokines, prior habitual activity, etc., than young aspiring athletes. Therefore, this study does not provide good evidence that variation at this locus influences likelihood of success in sport. On the other hand, Huuskonen et al. ${ }^{163}$ demonstrated that genotype CC of polymorphism rs7136446 of IGF1 gene increases the maximal force production.

Peroxisome proliferator-activated receptor (PPAR)delta (PPARD gene) and PPAR-gamma coactivator1-alpha (PPARGC1A gene) are determinants of mitochondrial function in animals and in vitro, and play a crucial role in training-induced muscle adaptation. PPAR-delta, in particular, regulates expression of genes involved in lipid and carbohydrate metabolism, affects insulin sensitivity by modifying glucose uptake in skeletal muscle. A functional $+294 \mathrm{~T} / \mathrm{C}$ polymorphism in this gene (allele $\mathrm{C}$ ) is associated with higher transcriptional activity compared to $\mathrm{T}$ allele. Akhmetov et al. ${ }^{164}$ reported a significantly higher frequency of PPARD $C$ allele in endurance-oriented athletes than in controls $(18.3 \%$ vs $12.1 \%$; $P<0.0001)$, showing that the $+294 \mathrm{~T} / \mathrm{C}$ polymorphism of PPARD gene is associated with predisposition to endurance performance. Moreover, Chiu et al. ${ }^{150}$ reported better performance in handgrip strength, 30- and 60-s sit-up tests, and standing long jump in Taiwanese adolescent girls with $P P A R D$ T/C genotype, whereas a combination of $A C E \mathrm{D} / \mathrm{D}, A C T N 3 \mathrm{R} / \mathrm{R}$ and PPARD T/T genotype have significantly greater performance in handgrip strength.

PPAR-gamma coactivator-1-alpha (PPARGC1A gene) is an important factor regulating the expression of genes for oxidative phosphorylation and ATP production in target tissues through coactivation of nuclear receptors. Muscle-specific expression of PGC-1 alpha improves the performance during voluntary as well as forced exercise challenges. Additionally, $P G C-1$ alpha transgenic mice exhibit an enhanced performance during a peak $\mathrm{VO}_{2}$ exercise test, demonstrating an increased peak oxidative capacity, or whole body oxygen uptake ${ }^{165}$. Maciejewska et al. ${ }^{23}$ investigated the genotype distribution of Gly482Ser polymorphism of PPARGC1A gene in Polish and Russian athletes, showing that its frequency is signifi- 
cantly lower in the athletes compared with unfit controls $(P<0.0001)$. The under-representation of $482 \mathrm{Ser}$ allele was observed among the endurance, strengthendurance, and sprint-strength athletes. Thus, the authors concluded that Gly482 allele may be associated with endurance performance, while 482Ser allele may affect the aerobic capacity.

The adrenergic receptors are involved in several performance-related pathways and are therefore of particular interest as candidate genes for performance phenotypes. The $\beta 2$-adrenergic receptor (ADRB2) gene is a candidate for variation in endurance performance levels because of its contribution to the regulation of energy expenditure and lipid mobilization from human adipose tissue ${ }^{166}$. The Arg16Gly polymorphism in this gene may be associated with endurance performance status in white men ${ }^{167}$.

The Nuclear Respiratory Factors NRF1 and NRF2 coordinate the expression of nuclear and mitochondrial genes relevant to mitochondrial biogenesis and respiration. Carriers of a polymorphism in the sequence of translation initiator ATG in the NFR2 gene have higher training response in running economy than noncarriers, thus potentially explaining some of the interindividual variance in endurance capacity ${ }^{168}$

The hypoxia inducible factors (HIFs) are a family of proteins regulating the mechanisms of response to hypoxia occurring in circumstances of increased oxygen demand, such as muscles working at high intensity. HIF-1alpha is the primary transcriptional response factor for acclimation to hypoxic stress, which up-regulates glycolysis and angiogenesis in response to low levels of tissue oxygenation. The increase of expression of erythropoietin and glycolytic enzyme genes, induced by HIFs, achieves high levels of anaerobic performances, allowing increase of anaerobic power output in a short-term period. Removal of HIF-1alpha causes an adaptive response in skeletal muscle akin to endurance training, and provides evidence for the suppression of mitochondrial biogenesis by HIF-1alpha in normal tissue ${ }^{169}$. Since HIF-2 alpha, encoded by the endothelial PAS domain protein1 (EPAS-1), is a sensor capable of integrating cardiovascular function, energetic demand, muscle activity and oxygen availability into physiological adaptation, DNA variants in EPAS-1 influence the relative contribution of aerobic and anaerobic metabolism and hence the maximum sustainable metabolic power for a given event duration ${ }^{170}$.

The haemoglobin plays a crucial role in endurance performance, because the increase in its concentration in blood is associated with enhanced $\mathrm{VO}_{2}$ max and endurance capacity, which is also proportional to the increase in the oxygen carrying capacity of the blood. Subjects homozygous for intron $2,+16 \mathrm{C} / \mathrm{C}$ or $551 \mathrm{C} / \mathrm{C}$ in the haemoglobin gene have decreased oxygen cost of running, thus explaining part of the individual variation in the cardiorespiratory adaptation to endurance training ${ }^{171}$.

Three quantitative trait loci have been related to glucose and insulin metabolism phenotypes in response to endurance training exercise. A promising locus for glucose effectiveness (an insulin-independent effect whereby glucose mediates its own disposal from plasma) influencing exercise training response was identified on $19 q 13$ at the skeletal muscle glycogen synthase (GYS1) gene locus, which regulates glycogen storage in skeletal muscles. Two additional possible loci on $6 p$ and $7 q$ were captured for disposition index, which measures overall glucose homeostasis exercise training responses ${ }^{172}$.

The acetylcholine receptor subtype M2 (CHRM2) plays a key role in the cardiac chronotropic response and DNA sequence variation at the CHRM2 locus is a potential modifier of heart rate recovery in the sedentary state and after short-term endurance training in healthy individuals ${ }^{173}$. In its role as an endothelial cell proliferation and migration factor, vascular endothelial growth factor (VEGF) can affect peripheral circulation. Therefore, individuals with at least one copy of the AAG or CGC promoter region haplotype have higher $\mathrm{VO}_{2}$ max before and after aerobic exercise training than subjects with only the AGG and/or CGG haplotype ${ }^{174}$.

The mitochondrial uncoupling proteins 2 and 3 (UCP2 and UCP3) can affect the physical performance, by negatively regulating the production of reactive oxygen species and mitochondrial ATP synthesis. Recently, Dhamrait et al. ${ }^{43}$ assessed the efficiency of skeletal muscle contraction, both before and after a period of endurance training, in 85 young, healthy, sedentary adults with UCP3-55C>T (rs1800849) and/or UCP2$866 \mathrm{G}>\mathrm{A}$ (rs659366) polymorphisms. The authors demonstrated that these polymorphisms at the UCP3/2 gene locus are associated with training-related improvements in skeletal muscle performance.

Interleukin-6 (IL-6) is involved in muscle repair and hypertrophy following exercise-induced damage ${ }^{175}$. The $-174 \mathrm{G} / \mathrm{C}$ polymorphism (rs1800795) of the IL6 gene is associated with increased transcriptional response in vitro ${ }^{9,176}$ and in vivo ${ }^{4}$ settings. Ruiz et al. ${ }^{177}$ evaluated the frequencies of -174 G/C genotype and allele in Spanish elite endurance and power athletes, and non-athletic controls. Both GG genotype and G allele were significantly higher in the power athletes than the endurance athletes or controls. On the other hand, there was no difference between the control and endurance athletes. Thus, the authors concluded that the $\mathrm{G}$ allele of the IL6 -174 G/C polymorphism may favour sprint/power sports phenotype, which is mainly characterized by muscle hypertrophy/strength. However, this association was not confirmed in a replication study performed on Israeli elite endurance and power athletes ${ }^{178}$.

Some other gene polymorphisms have been associated with sport performance, although results are still preliminary or controversial. These include polymorphisms in the alpha2a-adrenoceptor gene $(A D R A 2 A)^{179}$, bradykinin beta 2 receptor (BDKRB2) and endothelial nitric oxide synthase 3 (NOS3) genes $^{180}$, vitamin $\mathrm{D}$ receptor gene ${ }^{181,182}$, and ATPase, $\mathrm{Ca} 2+$ transporting, cardiac muscle, slow twitch 2 (ATP2A2), the NUAK family, SNF1-like kinase, 1 (NUAK1), and the protein phosphatase 1, catalytic subunit, gamma isoform (PPP1CC) genes ${ }^{183}$. 


\section{Conclusion}

According to Darwin's theory of natural selection, individuals with favourable traits are more likely to survive and reproduce than those without them. Today, it is accepted that genetics determines the response of an individual to the surrounding environment. However, the identification of the genetic background related to susceptibility to injuries and physical performance of the athletes is challenging. Recently, the development of technology for rapid DNA sequencing and genotyping has allowed the identification of some of the individual genetic variations that contribute to athletic performance and the onset of musculoskeletal injuries, particularly in tendon and ligament tissues. Although these findings could explain why an individual is able to excel in one sport discipline (i.e. sprint) rather than in a different one, and why an individual develops more injuries than another one, many other factors should be taken into account. Sport performances are also the result of hours spent in focused, prolonged, intensive training, and a favourable genotype is not enough to produce a champion. On the other hand, appropriate prevention strategies play a critical role in reducing injury rates, independently by the genetics.

Although further studies must be performed to establish influence and interaction of genes across a range of athletic parameters, genetic analyses will help to identify individuals with advantageous physiology, morphology and maybe psychology, those with a greater capacity to respond/adapt to training and those with a lower chance of suffering from injuries. Recently, the British Association of Sport and Exercise Sciences (BASES) Molecular Exercise Physiology Interest Group produced a position stand to advise on current issues in genetic research and testing in sport and exercise science (BASES position stand on Genetic Research and Testing in Sport and Exercise Science). This statement clearly highlights that genetic testing (i) might be useful for the development of genetic performance tests, (ii) may also be applied for pre-participation risk screening and may prevent sudden deaths during sport; (iii) might in future also be used to identify those who are most likely to benefit medically from exercise programmes; (iv) may become more important in anti-doping activities where it could be used for identification purposes (genetic fingerprinting) and more direct antidoping testing.

\section{References}

1. Longo UG, Rittweger J, Garau G, Radonic B, Gutwasser C, et al. No influence of age, gender, weight, height, and impact profile in achilles tendinopathy in masters track and field athletes. Am J Sports Med 2009; 37:1400-1405.

2. Ames PR, Longo UG, Denaro V, Maffulli N. Achilles tendon problems: not just an orthopaedic issue. Disabil Rehabil 2008; 30:1646-1650.

3. Herring SA, Nilson KL. Introduction to overuse injuries. Clin Sports Med 1987; 6:225-239.
4. Maffulli N, Longo UG, Gougoulias N, Loppini M, Denaro V. Long-term health outcomes of youth sports injuries. $\mathrm{Br} \mathrm{J}$ Sports Med 2010; 44:21-25.

5. Rees JD, Wilson AM, Wolman RL. Current concepts in the management of tendon disorders. Rheumatology (Oxford) 2006; 45:508-521.

6. Maffulli N, Khan KM, Puddu G. Overuse tendon conditions: time to change a confusing terminology. Arthroscopy 1998; 14:840-843.

7. Clancy W. Failed healing responses. In: W. Leadbetter, J. Buckwater and S. Gordon, Editors, Sports-Induced Inflammation: clinical and basic science concepts, American Orthopedic Society for Sports Medicine, Park Ridge (1989).

8. Maffulli N, Longo UG, Franceschi F, Rabitti C, Denaro V. Movin and Bonar scores assess the same characteristics of tendon histology. Clin Orthop Relat Res 2008; 466:1605-1611.

9. Maffulli N, Longo UG, Loppini M, Denaro V. Current treatment options for tendinopathy. Expert Opin Pharmacother 2010; 11:2177-2186.

10. Arya S, Kulig K. Tendinopathy Alters Mechanical and Material Properties of the Achilles Tendon. J Appl Physiol 2010; 108:670-675.

11. Longo UG, Franceschi F, Ruzzini L, Rabitti C, Morini S, et al. Light microscopic histology of supraspinatus tendon ruptures. Knee Surg Sports Traumatol Arthrosc 2007; 15:1390-1394.

12. Longo UG, Franceschi F, Ruzzini L, Rabitti C, Morini S, et al. Characteristics at haematoxylin and eosin staining of ruptures of the long head of the biceps tendon. $\mathrm{Br} J$ Sports Med 2009; 43:603-607.

13. Longo UG, Franceschi F, Ruzzini L, Rabitti C, Morini S, et al. Histopathology of the supraspinatus tendon in rotator cuff tears. Am J Sports Med 2008; 36:533-538.

14. Longo UG, Ronga M, Maffulli N. Acute ruptures of the achilles tendon. Sports Med Arthrosc 2009; 17:127-138.

15. Longo UG, Ronga M, Maffulli N. Achilles tendinopathy. Sports Med Arthrosc 2009; 17:112-126.

16. Rees JD, Maffulli N, Cook J. Management of tendinopathy. Am J Sports Med 2009; 37:1855-1867.

17. Garau G, Rittweger J, Mallarias P, Longo UG, Maffulli N. Traumatic patellar tendinopathy. Disabil Rehabil 2008 30:1616-1620.

18. Longo UG, Franceschi F, Spiezia F, Forriol F, Maffulli N, Denaro V. Triglycerides and total serum cholesterol in rotator cuff tears: do they matter? Br J Sports Med 2010; 44:948-951.

19. Longo UG, Oliva F, Denaro V, Maffulli N. Oxygen species and overuse tendinopathy in athletes. Disabil Rehabil 2008; 30:1563-1571.

20. Longo UG, Franceschi F, Ruzzini L, Spiezia F, Maffulli N, Denaro V. Higher fasting plasma glucose levels within the normoglycaemic range and rotator cuff tears. Br J Sports Med 2009; 43:284-287.

21. Lewis JS. Rotator cuff tendinopathy: A model for the continuum of pathology and related management. $\mathrm{Br} \mathrm{J}$ Sports Med 2010; 44:918-923.

22. Cook JL, Purdam CR. Is tendon pathology a continuum? A pathology model to explain the clinical presentation of loadinduced tendinopathy. Br J Sports Med 2009; 43:409-416.

23. Lippi G, Longo UG, Maffulli N. Genetics and sports. Br Med Bull 2010; 93:27-47.

24. Hoffmann A, Gross G. Tendon and ligament engineering in the adult organism: mesenchymal stem cells and gene-therapeutic approaches. Int Orthop 2007; 31:791-797.

25. Mann V, Hobson EE, Li B, Stewart TL, Grant SF, et al. A COL1A1 Sp1 binding site polymorphism predisposes to osteoporotic fracture by affecting bone density and quality. $J$ Clin Invest 2001; 107:899-907. 
26. Lian K, Zmuda JM, Nevitt MC, Lui L, Hochberg MC, et al. Type I collagen alpha1 Sp1 transcription factor binding site polymorphism is associated with reduced risk of hip osteoarthritis defined by severe joint space narrowing in elderly women. Arthritis Rheum 2005; 52:1431-1436.

27. Speer G SP, Kósa JP, Tabák AG, Folhoffer A, Fuszek P, Cseh $\mathrm{K}$, Lakatos $\mathrm{P}$. Myocardial infarction is associated with Spl binding site polymorphism of collagen type $1 \mathrm{~A} 1$ gene. Acta Cardiol 2006; 61:321-325.

28. Tilkeridis C BT, Garantziotis S, Stratakis CA. Association of a COL1A1 polymorphism with lumbar disc disease in young military recruits. J Med Genet 2005; 42:e44.

29. Skorupski P, Krol J, Starega J, Adamiak A, Jankiewicz K, Rechberger T. An alpha-1 chain of type I collagen Sp1-binding site polymorphism in women suffering from stress urinary incontinence. Am J Obstet Gynecol 2006; 194:346350.

30. Deak SB, van der Rest M, Prockop DJ. Altered helical structure of a homotrimer of alpha $1(\mathrm{I})$ chains synthesized by fibroblasts from a variant of osteogenesis imperfecta. Coll Relat Res 1985; 5:305-313.

31. Khoschnau S, Melhus H, Jacobson A, Rahme H, Bengtsson $\mathrm{H}$, et al. Type I collagen alpha1 Sp1 polymorphism and the risk of cruciate ligament ruptures or shoulder dislocations. Am J Sports Med 2008; 36:2432-2436.

32. Posthumus M, September AV, Keegan M, O'Cuinneagain D, Van der Merwe W, et al. Genetic risk factors for anterior cruciate ligament ruptures: COL1A1 gene variant. Br J Sports Med 2009; 43:352-356.

33. Posthumus M, September AV, Schwellnus MP, Collins M. Investigation of the Sp1-binding site polymorphism within the COL1A1 gene in participants with Achilles tendon injuries and controls. J Sci Med Sport 2009; 12:184-189.

34. Collins M, Posthumus M, Schwellnus MP. The COL1A1 gene and acute soft tissue ruptures. Br J Sports Med 2010; 44:1063-1064.

35. Mokone GG, Schwellnus MP, Noakes TD, Collins M. The COL5A1 gene and Achilles tendon pathology. Scand J Med Sci Sports 2006; 16:19-26.

36. September AV, Cook J, Handley CJ, van der Merwe L, Schwellnus MP, Collins M. Variants within the COL5A1 gene are associated with Achilles tendinopathy in two populations. Br J Sports Med 2009; 43:357-365.

37. Posthumus M, September AV, O'Cuinneagain D, van der Merwe W, Schwellnus MP, Collins M. The COL5A1 gene is associated with increased risk of anterior cruciate ligament ruptures in female participants. Am J Sports Med 2009; 37:2234-2240.

38. Collins M, Mokone GG, September AV, van der Merwe L, Schwellnus MP. The COL5A1 genotype is associated with range of motion measurements. Scand J Med Sci Sports 2009; 19:803-810.

39. Hildebrand KA, Frank CB, Hart DA. Gene intervention in ligament and tendon: current status, challenges, future directions. Gene Ther 2004; 11:368-378.

40. Niyibizi C, Kavalkovich K, Yamaji T, Woo SL. Type V collagen is increased during rabbit medial collateral ligament healing. Knee Surg Sports Traumatol Arthrosc 2000; 8:281285.

41. Kannus $P$, Natri A. Etiology and pathophysiology of tendon ruptures in sports. Scand J Med Sci Sports 1997; 7:107-112.

42. Greenspan DS, Pasquinelli AE. BstUI and Dpnll RFLPs at the COL5A1 gene. Hum Mol Genet 1994; 3:385.

43. Longo UG, Fazio V, Poeta ML, Rabitti C, Franceschi F, et al. Bilateral consecutive rupture of the quadriceps tendon in a man with BstUI polymorphism of the COL5A1 gene. Knee Surg Sports Traumatol Arthrosc 2010; 18:514-518.

44. Laguette MJ, Abrahams Y, Prince S, Collins M. Sequence variants within the 3 '-UTR of the COL5A1 gene alters mRNA stability: implications for musculoskeletal soft tissue injuries. Matrix Biol 2011; 30:338-345.

45. Whaley M. ACSM's Guidelines for Exercise Testing and Precription. Philadelphia: Lippincott Williams \& Wilkins 2006; 1366.

46. Knapik JJ, Jones BH, Bauman CL, Harris JM. Strength, flexibility and athletic injuries. Sports Med 1992; 14:277-288.

47. Wang SS, Whitney SL, Burdett RG, Janosky JE. Lower extremity muscular flexibility in long distance runners. J Orthop Sports Phys Ther 1993; 17:102-107.

48. Krivickas LS, Feinberg JH. Lower extremity injuries in college athletes: relation between ligamentous laxity and lower extremity muscle tightness. Arch Phys Med Rehabil 1996; 77:1139-1143.

49. Goeken LN, Hof AL. Instrumental straight-leg raising: results in healthy subjects. Arch Phys Med Rehabil 1993; 74:194-203.

50. Brown JC, Miller CJ, Schwellnus MP, Collins M. Range of motion measurements diverge with increasing age for COL5A1 genotypes. Scand J Med Sci Sports 2011; 21:e266-272.

51. Brown JC, Miller CJ, Posthumus M, Schwellnus MP, Collins M. The COL5A1 Gene, Ultra-Marathon Running Performance, and Range of Motion. Int J Sports Physiol Perform 2011; 6:485-496.

52. September AV, Posthumus M, van der Merwe L, Schwellnus M, Noakes TD, Collins M. The COL12A1 and COL14A1 genes and Achilles tendon injuries. Int J Sports Med 2008; 29:257-263.

53. Posthumus M, September AV, O'Cuinneagain D, van der Merwe W, Schwellnus MP, Collins M. The association between the COL12A1 gene and anterior cruciate ligament ruptures. Br J Sports Med 2010; 44:1160-1165.

54. Shaw LM, Olsen BR. FACIT collagens: diverse molecular bridges in extracellular matrices. Trends Biochem Sci 1991; 16:191-194

55. Gordon MK, Gerecke DR, Olsen BR. Type XII collagen: distinct extracellular matrix component discovered by cDNA cloning. Proc Natl Acad Sci USA 1987; 84:6040-6044.

56. Olsen BR. New insights into the function of collagens from genetic analysis. Curr Opin Cell Biol 1995; 7:720-727.

57. Young BB, Zhang G, Koch M, Birk DE. The roles of types XII and XIV collagen in fibrillogenesis and matrix assembly in the developing cornea. J Cell Biochem 2002; 87:208-220.

58. Birk DE, Fitch JM, Babiarz JP, Doane KJ, Linsenmayer TF. Collagen fibrillogenesis in vitro: interaction of types I and $\mathrm{V}$ collagen regulates fibril diameter. J Cell Sci 1990; 95(Pt4):649-657.

59. Dublet B, van der Rest M. Type XIV collagen, a new homotrimeric molecule extracted from fetal bovine skin and tendon, with a triple helical disulfide-bonded domain homologous to type IX and type XII collagens. J Biol Chem 1991; 266:6853-6858.

60. Schnittger S, Herbst H, Schuppan D, Dannenberg C, Bauer $\mathrm{M}$, Fonatsch $\mathrm{C}$. Localization of the undulin gene (UND) to human chromosome band 8q23. Cytogenet Cell Genet 1995; 68:233-234

61. Jozsa L, Balint JB, Kannus P, Reffy A, Barzo M. Distribution of blood groups in patients with tendon rupture. An analysis of 832 cases. J Bone Joint Surg Br 1989; 71:272-274.

62. Jozsa L, Kvist M, Balint BJ, Reffy A, Jarvinen M, et al. The role of recreational sport activity in Achilles tendon rupture. A clinical, pathoanatomical, and sociological study of 292 cases. Am J Sports Med 1989; 17:338-343.

63. Kujala UM, Jarvinen M, Natri A, Lehto M, Nelimarkka O, et al. ABO blood groups and musculoskeletal injuries. Injury 1992; 23:131-133.

64. Rocchi M, Archidiacono N, Romeo G, Saginati M, Zardi L. 
Assignment of the gene for human tenascin to the region q32q34 of chromosome 9. Hum Genet 1991; 86:621-623.

65. Mackie EJ. Molecules in focus: tenascin-C. Int J Biochem Cell Biol 1997; 29:1133-1137.

66. Jones FS, Jones PL. The tenascin family of ECM glycoproteins: structure, function, and regulation during embryonic development and tissue remodeling. Dev Dyn 2000; 218:235-259.

67. Chiquet M, Fambrough DM. Chick myotendinous antigen. I. A monoclonal antibody as a marker for tendon and muscle morphogenesis. J Cell Biol 1984; 98:1926-1936.

68. Chiquet M, Fambrough DM. Chick myotendinous antigen. II. A novel extracellular glycoprotein complex consisting of large disulfide-linked subunits. J Cell Biol 1984; 98:1937-1946.

69. Jarvinen TA, Jozsa L, Kannus $P$, Jarvinen TL, Kvist M, et al. Mechanical loading regulates tenascin-C expression in the osteotendinous junction. J Cell Sci 1999; 112(Pt18):31573166.

70. Mokone GG, Gajjar M, September AV, Schwellnus MP, Greenberg J, et al. The guanine-thymine dinucleotide repeat polymorphism within the tenascin-C gene is associated with achilles tendon injuries. Am J Sports Med 2005; 33:1016-1021.

71. Collins M, Raleigh SM. Genetic risk factors for musculoskeletal soft tissue injuries. Med Sport Sci 2009; 54:136-149.

72. September AV, Schwellnus MP, Collins M. Tendon and ligament injuries: the genetic component. $\mathrm{Br} \mathrm{J}$ Sports Med 2007; 41:241-246.

73. Raleigh SM, van der Merwe L, Ribbans WJ, Smith RK, Schwellnus MP, Collins M. Variants within the MMP3 gene are associated with Achilles tendinopathy: possible interaction with the COL5A1 gene. Br J Sports Med 2009; 43:514-520.

74. Somerville RP, Oblander SA, Apte SS. Matrix metalloproteinases: old dogs with new tricks. Genome Biol 2003; 4:216.

75. Birkedal-Hansen H, Moore WG, Bodden MK, Windsor LJ, Birkedal-Hansen B, et al. Matrix metalloproteinases: a review. Crit Rev Oral Biol Med 1993; 4:197-250.

76. Spurr NK, Gough AC, Gosden J, Rout D, Porteous DJ, et al. Restriction fragment length polymorphism analysis and assignment of the metalloproteinases stromelysin and collagenase to the long arm of chromosome 11. Genomics 1988; 2:119-127.

77. Ye S, Eriksson P, Hamsten A, Kurkinen M, Humphries SE, Henney AM. Progression of coronary atherosclerosis is associated with a common genetic variant of the human stromelysin-1 promoter which results in reduced gene expression. J Biol Chem 1996; 271:13055-13060.

78. Beyzade S, Zhang S, Wong YK, Day IN, Eriksson P, Ye S. Influences of matrix metalloproteinase-3 gene variation on extent of coronary atherosclerosis and risk of myocardial infarction. J Am Coll Cardiol 2003; 41:2130-2137.

79. Ye S, Patodi N, Walker-Bone K, Reading I, Cooper C, Dennison $\mathrm{E}$. Variation in the matrix metalloproteinase-3, $-7,-12$ and -13 genes is associated with functional status in rheumatoid arthritis. Int J Immunogenet 2007; 34:81-85.

80. Alfredson H, Lorentzon M, Backman S, Backman A, Lerner UH. cDNA-arrays and real-time quantitative PCR techniques in the investigation of chronic Achilles tendinosis. J Orthop Res 2003; $21: 970-975$.

81. Ireland D, Harrall R, Curry V, Holloway G, Hackney R, et al. Multiple changes in gene expression in chronic human Achilles tendinopathy. Matrix Biol 2001; 20:159-169.

82. Malila S, Yuktanandana P, Saowaprut S, Jiamjarasrangsi W, Honsawek S. Association between matrix metalloproteinase-3 polymorphism and anterior cruciate ligament ruptures. Genet Mol Res 2011; 10:4158-4165.

83. Posthumus M, Collins M, Cook J, Handley CJ, Ribbans WJ, et al. Components of the transforming growth factor-beta family and the pathogenesis of human Achilles tendon pathol- ogy - a genetic association study. Rheumatology (Oxford) 2010; 49:2090-2097.

84. Hou Y, Mao Z, Wei X, Lin L, Chen L, et al. The roles of TGFbeta1 gene transfer on collagen formation during Achilles tendon healing. Biochem Biophys Res Commun 2009; 383:235-239.

85. Rickert $\mathrm{M}$, Wang $\mathrm{H}$, Wieloch $\mathrm{P}$, Lorenz $\mathrm{H}$, Steck $\mathrm{E}$, et al. Adenovirus-mediated gene transfer of growth and differentiation factor-5 into tenocytes and the healing rat Achilles tendon. Connect Tissue Res 2005; 46:175-183.

86. Bolt P, Clerk AN, Luu HH, Kang Q, Kummer JL, et al. BMP14 gene therapy increases tendon tensile strength in a rat model of Achilles tendon injury. J Bone Joint Surg Am 2007; 89:1315-1320.

87. Mackey AL, Heinemeier KM, Koskinen SO, Kjaer M. Dynamic adaptation of tendon and muscle connective tissue to mechanical loading. Connect Tissue Res 2008; 49:165-168.

88. Vishnoi M, Pandey SN, Modi DR, Kumar A, Mittal B. Genetic susceptibility of epidermal growth factor $+61 A>G$ and transforming growth factor beta $1-509 \mathrm{C}>\mathrm{T}$ gene polymorphisms with gallbladder cancer. Hum Immunol 2008; 69:360-367.

89. Yuan X, Liao Z, Liu Z, Wang LE, Tucker SL, et al. Single nucleotide polymorphism at rs1982073:T869C of the TGFbeta 1 gene is associated with the risk of radiation pneumonitis in patients with non-small-cell lung cancer treated with definitive radiotherapy. J Clin Oncol 2009; 27:3370-3378.

90. Sharma S, Raby BA, Hunninghake GM, Soto-Quiros M, Avila L, et al. Variants in TGFB1, dust mite exposure, and disease severity in children with asthma. Am J Respir Crit Care Med 2009; 179:356-362.

91. Li H, Romieu I, Wu H, Sienra-Monge JJ, Ramirez-Aguilar M, et al. Genetic polymorphisms in transforming growth factor beta-1 (TGFB1) and childhood asthma and atopy. Hum Genet 2007; 121:529-538.

92. Shah R, Hurley CK, Posch PE. A molecular mechanism for the differential regulation of TGF-beta1 expression due to the common SNP -509C-T (c. -1347C > T). Hum Genet 2006; 120:461-469.

93. Langdahl BL, Uitterlinden AG, Ralston SH, Trikalinos TA, Balcells $\mathrm{S}$, et al. Large-scale analysis of association between polymorphisms in the transforming growth factor beta 1 gene (TGFB1) and osteoporosis: the GENOMOS study. Bone 2008; 42:969-981.

94. Koch W, Hoppmann P, Mueller JC, Schomig A, Kastrati A. Association of transforming growth factor-beta1 gene polymorphisms with myocardial infarction in patients with angiographically proven coronary heart disease. Arterioscler Thromb Vasc Biol 2006; 26:1114-1119.

95. Grainger DJ, Heathcote K, Chiano M, Snieder H, Kemp PR, et al. Genetic control of the circulating concentration of transforming growth factor type beta1. Hum Mol Genet 1999; 8:93-97.

96. Eliasson P, Fahlgren A, Aspenberg P. Mechanical load and BMP signaling during tendon repair: a role for follistatin? Clin Orthop Relat Res 2008; 466:1592-1597.

97. Mikic B. Multiple effects of GDF- 5 deficiency on skeletal tissues: implications for therapeutic bioengineering. Ann Biomed Eng 2004; 32:466-476.

98. Szczaluba K, Hilbert K, Obersztyn E, Zabel B, Mazurczak T, Kozlowski K. Du Pan syndrome phenotype caused by heterozygous pathogenic mutations in CDMP1 gene. Am J Med Genet A 2005; 138:379-383.

99. Schwabe GC, Turkmen S, Leschik G, Palanduz S, Stover $B$, et al. Brachydactyly type $C$ caused by a homozygous missense mutation in the prodomain of CDMP1. Am J Med Genet A 2004; 124A:356-363.

100. Basit S, Naqvi SK, Wasif N, Ali G, Ansar M, Ahmad W. A novel insertion mutation in the cartilage-derived morphogenetic protein-1 (CDMP1) gene underlies Grebe-type chon- 
drodysplasia in a consanguineous Pakistani family. BMC Med Genet 2008; 9:102.

101. Wolfman NM, Hattersley G, Cox K, Celeste AJ, Nelson R, et al. Ectopic induction of tendon and ligament in rats by growth and differentiation factors 5,6 , and 7 , members of the TGF-beta gene family. J Clin Invest 1997; 100:321-330.

102. Chapman K, Takahashi A, Meulenbelt I, Watson C, Rodriguez-Lopez J, et al. A meta-analysis of European and Asian cohorts reveals a global role of a functional SNP in the 5' UTR of GDF5 with osteoarthritis susceptibility. Hum Mol Genet 2008; 17:1497-1504.

103. Dai J, Shi D, Zhu P, Qin J, Ni H, et al. Association of a single nucleotide polymorphism in growth differentiate factor 5 with congenital dysplasia of the hip: a case-control study. Arthritis Res Ther 2008; 10:R126.

104. Miyamoto Y, Mabuchi A, Shi D, Kubo T, Takatori Y, et al. A functional polymorphism in the 5' UTR of GDF5 is associated with susceptibility to osteoarthritis. Nat Genet 2007; 39:529-533

105. Southam L, Rodriguez-Lopez J, Wilkins JM, Pombo-Suarez M, Snelling S, et al. An SNP in the 5'-UTR of GDF5 is associated with osteoarthritis susceptibility in Europeans and with in vivo differences in allelic expression in articular cartilage. Hum Mol Genet 2007; 16:2226-2232.

106. Egli RJ, Southam L, Wilkins JM, Lorenzen I, PomboSuarez M, et al. Functional analysis of the osteoarthritis susceptibility-associated GDF5 regulatory polymorphism. Arthritis Rheum 2009; 60:2055-2064.

107. Bray MS, Hagberg JM, Perusse L, Rankinen T, Roth SM, et al. The human gene map for performance and health-related fitness phenotypes: the 2006-2007 update. Med Sci Sports Exerc 2009; 41:35-73.

108. Myerson S, Hemingway H, Budget R, Martin J, Humphries $\mathrm{S}$, Montgomery $\mathrm{H}$. Human angiotensin l-converting enzyme gene and endurance performance. J Appl Physiol 1999; 87:1313-1316.

109. Woods D, Hickman M, Jamshidi Y, Brull D, Vassiliou V, et al. Elite swimmers and the $D$ allele of the ACE I/D polymorphism. Hum Genet 2001; 108:230-232.

110. Montgomery HE, Marshall R, Hemingway H, Myerson S, Clarkson $\mathrm{P}$, et al. Human gene for physical performance. Nature 1998; 393:221-222.

111. Gordon SE, Davis BS, Carlson CJ, Booth FW. ANG II is required for optimal overload-induced skeletal muscle hypertrophy. Am J Physiol Endocrinol Metab 2001; 280:E150-159.

112. Jones A, Montgomery HE, Woods DR. Human performance: a role for the ACE genotype? Exerc Sport Sci Rev 2002; 30:184-190.

113. Wagner H, Thaller S, Dahse R, Sust M. Biomechanical muscle properties and angiotensin-converting enzyme gene polymorphism: a model-based study. Eur J Appl Physiol 2006; 98:507-515

114. Yamin C, Amir O, Sagiv M, Attias E, Meckel Y, et al. ACE ID genotype affects blood creatine kinase response to eccentric exercise. J Appl Physiol 2007; 103:2057-2061.

115. Giaccaglia V, Nicklas B, Kritchevsky S, Mychalecky J, Messier $\mathrm{S}$, et al. Interaction between angiotensin converting enzyme insertion/deletion genotype and exercise training on knee extensor strength in older individuals. Int J Sports Med 2008; 29:40-44.

116. Williams AG, Rayson MP, Jubb M, World M, Woods DR, et al. The ACE gene and muscle performance. Nature 2000; 403:614

117. Collins M, Xenophontos SL, Cariolou MA, Mokone GG, Hudson $D E$, et al. The ACE gene and endurance performance during the South African Ironman Triathlons. Med Sci Sports Exerc 2004; 36:1314-1320.

118. Nazarov IB, Woods DR, Montgomery HE, Shneider OV,
Kazakov VI, et al. The angiotensin converting enzyme I/D polymorphism in Russian athletes. Eur J Hum Genet 2001; 9:797-801.

119. Costa AM, Silva AJ, Garrido ND, Louro H, de Oliveira RJ, Breitenfeld L. Association between ACE D allele and elite short distance swimming. Eur J Appl Physiol 2009; 106:785-790.

120. Tsianos G, Sanders J, Dhamrait S, Humphries S, Grant S, Montgomery $\mathrm{H}$. The ACE gene insertion/deletion polymorphism and elite endurance swimming. Eur J Appl Physiol 2004; 92:360-362.

121. Papadimitriou ID, Papadopoulos C, Kouvatsi A, Triantaphyllidis C. The ACE I/D polymorphism in elite Greek track and field athletes. J Sports Med Phys Fitness 2009; 49:459-463.

122. Amir O, Amir R, Yamin C, Attias E, Eynon N, et al. The ACE deletion allele is associated with Israeli elite endurance athletes. Exp Physiol 2007; 92:881-886.

123. Scott RA, Moran C, Wilson RH, Onywera V, Boit MK, et al. No association between Angiotensin Converting Enzyme (ACE) gene variation and endurance athlete status in Kenyans. Comp Biochem Physiol A Mol Integr Physiol 2005; 141:169-175.

124. Ash Gl, Scott RA, Deason M, Dawson TA, Wolde B, et al. No association between ACE gene variation and endurance athlete status in Ethiopians. Med Sci Sports Exerc 2011; 43:590-597.

125. De Moor MH, Spector TD, Cherkas LF, Falchi M, Hottenga $\mathrm{JJ}$, et al. Genome-wide linkage scan for athlete status in 700 British female DZ twin pairs. Twin Res Hum Genet 2007; 10:812-820.

126. MacArthur DG, North KN. A gene for speed? The evolution and function of alpha-actinin-3. Bioessays 2004; 26:786-795.

127. Berman $Y$, North KN. A gene for speed: the emerging role of alpha-actinin-3 in muscle metabolism. Physiology (Bethesda) 25:250-259.

128. Beggs AH, Byers TJ, Knoll JH, Boyce FM, Bruns GA, Kunkel LM. Cloning and characterization of two human skeletal muscle alpha-actinin genes located on chromosomes 1 and 11 . J Biol Chem 1992; 267:9281-9288.

129. Blanchard A, Ohanian V, Critchley D. The structure and function of alpha-actinin. J Muscle Res Cell Motil 1989; 10:280-289.

130. Yang N, MacArthur DG, Gulbin JP, Hahn AG, Beggs AH, et al. ACTN3 genotype is associated with human elite athletic performance. Am J Hum Genet 2003; 73:627-631.

131. Agbulut $O$, Noirez P, Beaumont F, Butler-Browne G. Myosin heavy chain isoforms in postnatal muscle development of mice. Biol Cell 2003; 95:399-406.

132. Druzhevskaya AM, Ahmetov, II, Astratenkova IV, Rogozkin VA. Association of the ACTN3 R577X polymorphism with power athlete status in Russians. Eur J Appl Physiol 2008; 103:631-634.

133. Niemi AK, Majamaa K. Mitochondrial DNA and ACTN3 genotypes in Finnish elite endurance and sprint athletes. Eur $J$ Hum Genet 2005; 13:965-969.

134. Roth SM, Walsh S, Liu D, Metter EJ, Ferrucci L, Hurley BF. The ACTN3 R577X nonsense allele is under-represented in elite-level strength athletes. Eur J Hum Genet 2008; 16:391-394.

135. Santiago C, Gonzalez-Freire M, Serratosa L, Morate FJ, Meyer T, et al. ACTN3 genotype in professional soccer players. Br J Sports Med 2008; 42:71-73.

136. MacArthur DG, Seto JT, Raftery JM, Quinlan KG, Huttley GA, et al. Loss of ACTN3 gene function alters mouse muscle metabolism and shows evidence of positive selection in humans. Nat Genet 2007; 39:1261-1265.

137. Vincent B, De Bock K, Ramaekers M, Van den Eede E, Van Leemputte M, et al. ACTN3 (R577X) genotype is associated with fiber type distribution. Physiol Genomics 2007; 32:58-63. 
138. MacArthur DG, Seto JT, Chan S, Quinlan KG, Raftery JM, et al. An Actn3 knockout mouse provides mechanistic insights into the association between alpha-actinin-3 deficiency and human athletic performance. Hum Mol Genet 2008; 17:1076-1086.

139. Papadimitriou ID, Papadopoulos C, Kouvatsi A, Triantaphyllidis $C$. The ACTN3 gene in elite Greek track and field athletes. Int J Sports Med 2008; 29:352-355.

140. Moran CN, Yang N, Bailey ME, Tsiokanos A, Jamurtas A, et al. Association analysis of the ACTN3 R577X polymorphism and complex quantitative body composition and performance phenotypes in adolescent Greeks. Eur J Hum Genet 2007; 15:88-93.

141. Eynon N, Duarte JA, Oliveira J, Sagiv M, Yamin C, et al. ACTN3 R577X polymorphism and Israeli top-level athletes. Int J Sports Med 2009; 30:695-698.

142. Muniesa CA, Gonzalez-Freire M, Santiago C, Lao JI, Buxens $A$, et al. World-class performance in lightweight rowing: is it genetically influenced? A comparison with cyclists, runners and non-athletes. Br J Sports Med 44:898-901.

143. Ahmetov, II, Druzhevskaya AM, Astratenkova IV, Popov DV, Vinogradova OL, Rogozkin VA. The ACTN3 R577X polymorphism in Russian endurance athletes. Br J Sports Med 44:649-652.

144. Lucia A, Gomez-Gallego F, Santiago C, Bandres F, Earnest $\mathrm{C}$, et al. ACTN3 genotype in professional endurance cyclists. Int J Sports Med 2006; 27:880-884.

145. Saunders CJ, September AV, Xenophontos SL, Cariolou MA, Anastassiades LC, et al. No association of the ACTN3 gene R577X polymorphism with endurance performance in Ironman Triathlons. Ann Hum Genet 2007; 71:777-781.

146. Yang N, MacArthur DG, Wolde B, Onywera VO, Boit MK, et al. The ACTN3 R577X polymorphism in East and West African athletes. Med Sci Sports Exerc 2007; 39:1985-1988.

147. Paparini A, Ripani M, Giordano GD, Santoni D, Pigozzi F, Romano-Spica V. ACTN3 genotyping by real-time PCR in the Italian population and athletes. Med Sci Sports Exerc 2007; 39:810-815.

148. Shang X, Huang C, Chang Q, Zhang L, Huang T. Association between the ACTN3 R577X polymorphism and female endurance athletes in China. Int J Sports Med 31:913-916.

149. Ahmetov, II, Druzhevskaya AM, Lyubaeva EV, Popov DV, Vinogradova OL, Williams AG. The dependence of preferred competitive racing distance on muscle fibre type composition and ACTN3 genotype in speed skaters. Exp Physiol 2011; 96:1302-1310.

150. Chiu LL, Chen TW, Hsieh SS, Hsieh LL. ACE I/D, ACTN3 R577X, PPARD T294C and PPARGC1A Gly482Ser polymorphisms and physical fitness in Taiwanese late adolescent girls. J Physiol Sci 2012; 62:115-121.

151. Gineviciene V, Pranculis A, Jakaitiene A, Milasius K, Kucinskas V. Genetic variation of the human ACE and ACTN3 genes and their association with functional muscle properties in Lithuanian elite athletes. Medicina (Kaunas) 2011; 47:284-290.

152. Echegaray M, Rivera MA. Role of creatine kinase isoenzymes on muscular and cardiorespiratory endurance: genetic and molecular evidence. Sports Med 2001; 31:919-934.

153. Bouchard C, Chagnon M, Thibault MC, Boulay MR, Marcotte $\mathrm{M}$, et al. Muscle genetic variants and relationship with performance and trainability. Med Sci Sports Exerc 1989;21:71-77.

154. Zhou DQ, Hu Y, Liu G, Gong L, Xi Y, Wen L. Muscle-specific creatine kinase gene polymorphism and running economy responses to an 18-week 5000-m training programme. Br J Sports Med 2006; 40:988-991.

155. Miranda-Vilela AL, Akimoto AK, Lordelo GS, Pereira LC Grisolia CK, Klautau-Guimaraes Mde N. Creatine kinase MM Taql and methylenetetrahydrofolate reductase C677T and
A1298C gene polymorphisms influence exercise-induced Creactive protein levels. Eur J Appl Physiol 2012; 112:941-950.

156. Miranda-Vilela AL, Akimoto AK, Lordelo GS, Pereira LC, Grisolia CK, Klautau-Guimaraes Mde N. Creatine kinase MM Taql and methylenetetrahydrofolate reductase C677T and A1298C gene polymorphisms influence exercise-induced Creactive protein levels. Eur J Appl Physiol 2012; 112:183-192.

157. Clarkson PM, Hoffman EP, Zambraski E, Gordish-Dressman $\mathrm{H}$, Kearns $\mathrm{A}$, et al. ACTN3 and MLCK genotype associations with exertional muscle damage. J Appl Physiol 2005; 99:564-569.

158. Rico-Sanz J, Rankinen T, Joanisse DR, Leon AS, Skinner JS, et al. Associations between cardiorespiratory responses to exercise and the C34T AMPD1 gene polymorphism in the HERITAGE Family Study. Physiol Genomics 2003; 14:161-166.

159. Rubio JC, Perez M, Mate-Munoz JL, Garcia-Consuegra I, Chamorro-Vina C, et al. AMPD1 Genotypes and Exercise Capacity in McArdle Patients. Int J Sports Med 2008; 29:331-5.

160. Cieszczyk P, Eider J, Ostanek M, Leonska-Duniec A, Ficek $\mathrm{K}$, et al. Is the C34T polymorphism of the AMPD1 gene associated with athlete performance in rowing? Int J Sports Med 2011; 32:987-991.

161. Cieszczyk P, Ostanek M, Leonska-Duniec A, Sawczuk M, Maciejewska A, et al. Distribution of the AMPD1 C34T polymorphism in Polish power-oriented athletes. J Sports Sci 2012; 30:31-35.

162. Kostek MC, Delmonico MJ, Reichel JB, Roth SM, Douglass $\mathrm{L}$, et al. Muscle strength response to strength training is influenced by insulin-like growth factor 1 genotype in older adults. J Appl Physiol 2005; 98:2147-2154.

163. Huuskonen A, Lappalainen J, Oksala N, Santtila M, Hakkinen $\mathrm{K}$, et al. Common genetic variation in the IGF1 associates with maximal force output. Med Sci Sports Exerc 2011; 43:2368-2374.

164. Akhmetov, II, Astranenkova IV, Rogozkin VA. Association of PPARD gene polymorphism with human physical performance. Mol Biol (Mosk) 2007; 41:852-857.

165. Calvo JA, Daniels TG, Wang X, Paul A, Lin J, et al. Musclespecific expression of PPARgamma coactivator-1alpha improves exercise performance and increases peak oxygen uptake. J Appl Physiol 2008; 104:1304-1312.

166. Wolfarth B, Rivera MA, Oppert JM, Boulay MR, Dionne FT, et al. A polymorphism in the alpha2a-adrenoceptor gene and endurance athlete status. Med Sci Sports Exerc 2000; 32:1709-1712.

167. Wolfarth B, Rankinen T, Muhlbauer S, Scherr J, Boulay MR, et al. Association between a beta2-adrenergic receptor polymorphism and elite endurance performance. Metabolism 2007; 56:1649-1651.

168. He Z, Hu Y, Feng L, Lu Y, Liu G, et al. NRF2 genotype improves endurance capacity in response to training. Int J Sports Med 2007; 28:717-721.

169. Mason SD, Rundqvist H, Papandreou I, Duh R, McNulty WJ, et al. HIF-1alpha in endurance training: suppression of oxidative metabolism. Am J Physiol Regul Integr Comp Physiol 2007; 293:R2059-2069

170. Henderson J, Withford-Cave JM, Duffy DL, Cole SJ, Sawyer $\mathrm{NA}$, et al. The EPAS1 gene influences the aerobic-anaerobic contribution in elite endurance athletes. Hum Genet 2005 118:416-423.

171. He Z, Hu Y, Feng L, Lu Y, Liu G, et al. Polymorphisms in the HBB gene relate to individual cardiorespiratory adaptation in response to endurance training. $\mathrm{Br} \mathrm{J}$ Sports Med 2006; 40:998-1002.

172. An P, Teran-Garcia M, Rice T, Rankinen T, Weisnagel SJ, et al. Genome-wide linkage scans for prediabetes phenotypes in response to 20 weeks of endurance exercise training in 
non-diabetic whites and blacks: the HERITAGE Family Study Diabetologia 2005; 48:1142-1149.

173. Hautala AJ, Rankinen T, Kiviniemi AM, Makikallio TH, Huikuri HV, et al. Heart rate recovery after maximal exercise is associated with acetylcholine receptor M2 (CHRM2) gene polymorphism. Am J Physiol Heart Circ Physiol 2006; 291:H459-466.

174. Prior SJ, Hagberg JM, Paton CM, Douglass LW, Brown MD, et al. DNA sequence variation in the promoter region of the VEGF gene impacts VEGF gene expression and maximal oxygen consumption. Am J Physiol Heart Circ Physiol 2006; 290:H1848-1855.

175. Helge JW, Stallknecht B, Pedersen BK, Galbo H, Kiens B, Richter EA. The effect of graded exercise on IL-6 release and glucose uptake in human skeletal muscle. J Physiol 2003; 546:299-305.

176. Terry CF, Loukaci V, Green FR. Cooperative influence of genetic polymorphisms on interleukin 6 transcriptional regulation. J Biol Chem 2000; 275:18138-18144.

177. Ruiz JR, Buxens A, Artieda M, Arteta D, Santiago C, et al. The $-174 \mathrm{G} / \mathrm{C}$ polymorphism of the IL6 gene is associated with elite power performance. J Sci Med Sport 2010; 13:549-553

178. Eynon N, Ruiz JR, Meckel Y, Santiago C, Fiuza-Luces C, et al. Is the $-174 \mathrm{C} / \mathrm{G}$ polymorphism of the IL6 gene asso- ciated with elite power performance? A replication study with two different Caucasian cohorts. Exp Physiol 2011; 96:156162.

179. Wolfarth B, Rivera MA, Oppert JM, Boulay MR, Dionne FT, et al. A polymorphism in the alpha2a-adrenoceptor gene and endurance athlete status. Med Sci Sports Exerc 2000; 32:1709-1712.

180. Saunders CJ, Xenophontos SL, Cariolou MA, Anastassiades LC, Noakes TD, Collins M. The bradykinin beta 2 receptor (BDKRB2) and endothelial nitric oxide synthase 3 (NOS3) genes and endurance performance during Ironman Triathlons. Hum Mol Genet 2006; 15:979-987.

181. Wang P, Ma LH, Wang HY, Zhang W, Tian Q, et al. Association between polymorphisms of vitamin $\mathrm{D}$ receptor gene Apal, Bsml and Taql and muscular strength in young Chinese women. Int J Sports Med 2006; 27:182-186.

182. Micheli ML, Gulisano M, Morucci G, Punzi T, Ruggiero M, et al. Angiotensin-converting enzyme/vitamin $D$ receptor gene polymorphisms and bioelectrical impedance analysis in predicting athletic performances of Italian young soccer players. J Strength Cond Res 2011; 25:2084-2091.

183. Windelinckx A, De Mars G, Huygens W, Peeters MW, Vincent $B$, et al. Identification and prioritization of NUAK1 and PPP1CC as positional candidate loci for skeletal muscle strength phenotypes. Physiol Genomics 2011; 43:981-992. 